Therapy in sport

Manuscript Number: PTIS-15104R1

Title: The Pectoralis Minor Muscle and Shoulder Movement-Related Impairments and Pain: Rationale, Assessment and Management

Article Type: Masterclass

Keywords: adaptive shortening; soft tissue tightness; scapular dyskinesis Corresponding Author: Mr. Nuno Valente Morais, PT, MSc

Corresponding Author's Institution: Polytechnic Institute of Leiria, School of Health Sciences

First Author: Nuno Valente Morais, PT, MSC

Order of Authors: Nuno Valente Morais, PT, MSc; Joana Cruz, MSc

Abstract: The adaptive shortening or tightness of the pectoralis minor muscle (PMm) is one of the potential biomechanical mechanisms associated with altered scapular alignment at rest and scapular motion during arm elevation (scapular dyskinesis) in patients with shoulder complaints. This masterclass briefly reviews the role of the PMm in shoulder movement-related impairments and provides a critical overview of the assessment of PMm tightness and the conventional approaches to increase its resting length and extensibility. A rehabilitation approach focused on PMm stretching and simultaneous optimization of the kinematic chain of arm elevation is also discussed, hoping to improve the management of shoulder movement-related impairments and pain. 
Nuno Valente Morais

Rua Engenheiro Duarte Pacheco, 19C, Fração AC

3850-040 Albergaria-a-Velha, Portugal

Telephone: (+351) 919528026

Email: rpgnunomorais@gmail.com

Subject: Submission of a manuscript for possible publication

Dear Editor-in-Chief of Physical Therapy in Sports

Professor Zoe Hudson

I herewith enclose the revision of a Masterclass for consideration and possible publication in Physical Therapy in Sports. We thank the editorial office and the reviewers for the time you have spent considering our paper. We have attempted to address reviewers' specific recommendations, commentaries and criticisms and would like to express gratitude for giving the opportunity to improve the quality of our paper. We found the reviews valuable and reasonable as well. Please find enclosed the revised version of the manuscript, as well as the list of amendments that have been performed. In the blinded version of the manuscript we have included the line numbers directly from the text processor, as requested by one of the reviewers, to facilitate the review process and communication between reviewers and authors. In addition, we have highlighted the most significant changes in bold.

\section{Title: The Pectoralis Minor Muscle and Shoulder Movement-Related Impairments and Pain: Rationale, Assessment and Management}

Nuno Morais ${ }^{1}$, MSc \& Joana Cruz ${ }^{1,2}$, MSc

${ }^{1}$ Polytechnic Institute of Leiria, School of Health Sciences (ESSLei - IPL), Department of Health Technologies, Campus 2 - Morro do Lena - Alto do Vieiro, 2411-901 Leiria, Portugal. Email: rpgnunomorais@gmail.com 
${ }^{2}$ School of Health Sciences of the University of Aveiro (ESSUA), Campus Universitário de Santiago, Agras do Crasto, Edifício 30, 3810-193 Aveiro, Portugal. Email: joana.cruz@ua.pt

\section{Acknowledgements}

The authors certify that they have no affiliations with or financial involvement in any organization or entity with a direct financial interest in the subject matter or materials discussed in the manuscript. A special thanks to the volunteers that kindly served as models for the figures illustrating the demonstration of the practice.

Address correspondence to: Nuno Valente Morais, Rua Engenheiro Duarte Pacheco, 19C, Fração AC, 3850-040 Albergaria-a-Velha, Portugal.

E-mail: rpgnunomorais@gmail.com

Yours sincerely, Nuno Morais 


\section{Conflict of interest statement}

The authors certify that they have no affiliations with or financial involvement in any organisation or entity with a direct financial interest in the subject matter or materials discussed in the manuscript. 


\section{The Pectoralis Minor Muscle and Shoulder Movement-Related} Impairments and Pain: Rationale, Assessment and Management

Nuno Morais ${ }^{1}$, MSc \& Joana Cruz ${ }^{1,2}$, MSc

${ }^{1}$ Polytechnic Institute of Leiria, School of Health Sciences (ESSLei - IPL), Department of Health Technologies, Campus 2 - Morro do Lena - Alto do Vieiro, 2411-901 Leiria, Portugal. Email: rpgnunomorais@gmail.com

${ }^{2}$ School of Health Sciences of the University of Aveiro (ESSUA), Campus Universitário de Santiago, Agras do Crasto, Edifício 30, 3810-193 Aveiro, Portugal. Email: joana.cruz@ua.pt

\section{Acknowledgements}

The authors certify that they have no affiliations with or financial involvement in any organization or entity with a direct financial interest in the subject matter or materials discussed in the manuscript. A special thanks to the volunteers that kindly served as models for the figures illustrating the demonstration of the practice.

Address correspondence to: Nuno Valente Morais, Rua Engenheiro Duarte Pacheco, 19C, Fração AC, 3850-040 Albergaria-a-Velha, Portugal.

E-mail:rpgnunomorais@gmail.com 


\section{The Pectoralis Minor Muscle and Shoulder Movement-Related}

2 Impairments and Pain: Rationale, Assessment and Management

3

\section{Abstract}

5 The adaptive shortening or tightness of the pectoralis minor muscle (PMm) is

6 one of the potential biomechanical mechanisms associated with altered

7 scapular alignment at rest and scapular motion during arm elevation

8 (scapular dyskinesis) in patients with shoulder complaints. This masterclass

9 briefly reviews the role of the PMm in shoulder movement-related

10 impairments and provides a critical overview of the assessment of PMm

11 tightness and the conventional approaches to increase its resting length and

12 extensibility. A rehabilitation approach focused on PMm stretching and

13 simultaneous optimization of the kinematic chain of arm elevation is also

14 discussed, hoping to improve the management of shoulder movement-

15 related impairments and pain.

17 Key Words: adaptive shortening; soft tissue tightness; scapular dyskinesis

20 Introduction

21 Pain and disability of the shoulder complex are common reasons for

22 seeking musculoskeletal and sports physical therapists. Most often pain and

23 disability are associated with movement; thus, correcting movement related-

24 impairments is considered a key strategy for achieving optimal outcomes

25 (Ludewig, Lawrence, \& Braman, 2013). Abnormal scapular position and

26 motion, commonly termed as scapular dyskinesis or scapular dysfunction, 
27 may contribute to alter the amount and the precision of shoulder movements,

28 and be the cause or the consequence of pain and functional loss in patients

29 with glenohumeral pathologies such as shoulder impingement, rotator cuff

30 tendinopathy or tears, and adhesive capsulitis (Ludewig \& Reynolds, 2009;

31 Ratcliffe, Pickering, McLean, \& Lewis, 2014). The adaptive shortening or

32 tightness of the pectoralis minor muscle (PMm) has been considered as one

33 of the potential mechanisms for altering scapular kinematics (Ludewig \&

34 Reynolds, 2009), hence addressing PMm tightness is often considered in

35 rehabilitation programs aiming to improve shoulder function and pain. Yet,

36 clinicians' ability to assess and treat PMm tightness has been limited by the

37 challenges of its anatomical location and function.

38 The aim of this masterclass is to outline a kinesiopathologic and,

39 therefore, a rehabilitation approach for the management of PMm tightness in

40 shoulder movement-related impairments and pain. Firstly, the most relevant

41 literature relating PMm tightness to shoulder pathologies with focus on

42 scapular dyskinesis will be reviewed. Secondly, a critical overview of the

43 existing measurement techniques to assess PMm tightness will be

44 performed. Finally, the conventional approaches to improve PMm length and

45 extensibility will be discussed and a more comprehensive rehabilitation

46 approach will be provided.

$48 \quad$ Search strategy

49 For preparing the review components of this masterclass, an

50 electronic literature search was performed in Pubmed database using a

51 combination of the terms "pectoralis minor", "length", "short", "tight", 
52 “stiff”, "stretch”, “posture”, "scapula”, “kinematic”, “pain”, "symptom”

53 in titles and abstracts. All the relevant abstracts were screened by the

54 first author and those not related to posture/movement-related

55 dysfunctions (e.g., pathoanatomic or neurovascular disorders) or PMm

56 length measurement properties or conservative interventions were

57 excluded from the pool of results. References of the remaining articles

58 were also searched for relevant content. Additional online searches

59 were performed in Google Scholar using the same aforementioned

60 terms. The last search was run on $21 / 08 / 2015$. Relevant articles were

61 then read carefully and are presented in the manuscript, whenever

62 appropriate.

63

64 Pectoralis minor muscle tightness: functional and clinical relevance

65 Based mainly on observations of the anatomical position and

66 orientation of the muscle fibers, it has been hypothesized that adaptive

67 shortening or tightness of the PMm may contribute to internally rotate,

68 anteriorly tilt and downwardly rotate the scapula, and protract and depress

69 the shoulder girdle (Burkhart, Morgan, \& Kibler, 2003; Kendall, McCreary,

70 Provance, Rodgers, \& Romani, 2005; Kisner \& Colby, 2007; Novak \&

71 Mackinnon, 1997; Sahrmann, 2002). Several clinicians conjectured that

72 such relatively fixed forward and downward scapular positioning may

73 place PMm antagonist muscles (e.g., lower trapezius) in an elongated

74 and weakened position, contribute to limit the amount and precision of

75 posterior and elevation movements of the scapula during arm

76 elevation, and be involved in the development or perpetuation of 
77 abnormal stress and healing in shoulder tissues (e.g., subacromial

78 tissues) and eventually pain (Burkhart, et al., 2003; Cools, et al., 2010;

79 W. Benjamin Kibler, Sciascia, \& Wilkes, 2012; McClain, Tucker, \&

80 Hornor, 2012; Sahrmann, 2002). Although many physical therapists

81 guide their practice by the postural, muscle and movement imbalances

82 model for the management of painful syndromes in the shoulder region

83 (e.g., subacromial pain syndrome) and upper body quadrant, evidence

84 of a kinesiopathologic mechanism of shoulder injuries and pain is yet

85 to be proven (Jeremy S Lewis, 2011). To date, there are no robust

86 longitudinal studies that can validate the kinesiopathologic chain

87 theorized above. Without the ability to follow human subjects

88 prospectively, it is difficult to discern if alterations found in PMm length

89 and scapular kinematics are compensatory or contributory to shoulder

90 movement impairments and pain. A number of cross-sectional studies

91 partially supports the rationale (J. D. Borstad, 2006; J. D. Borstad \&

92 Ludewig, 2005) nevertheless definitive research is required. Figure 1

93 summarizes the associations between PMm tightness, altered scapular

94 position and motion, potential changes in glenohumeral

95 arthrokinematics, abnormal stresses in tissues and painful syndromes

96 that have been documented. Each link will be discussed next,

97 considering also local and regional biomechanical factors that may

98 contribute to shorten the PMm. Figure 1 also serves as a framework to

99 guide the assessment and intervention proposed later in this

100 manuscript. 

postures and adaptive shortening of the PMm

The development of PMm tightness has been mostly based on the

105 principle that adaptive changes in the muscle belly will occur over time when

106 the muscle is chronically exposed to repetitive movements of the scapula in

107 forward and downward directions or maintained in a static shortened position

108 for long periods (J. D. Borstad \& Ludewig, 2005 Borstad, 2006 \#3833;

109 Burkhart, et al., 2003; Kendall, et al., 2005; Novak \& Mackinnon, 1997;

110 Sahrmann, 2002). There is emerging evidence suggesting that chronic

111 overhead throwing may lead to adaptive shortening of the PMm. In a study

112 aimed to describe the profile of the scapulothoracic position and strength in 113 asymptomatic elite tennis adolescent players ( $n=35,19$ girls), Cools et al

114 (2010) found a shorter PMm on the dominant arm when compared with the

115 nondominant arm. McClain et al. (2012) compared the resting scapular

116 position in the sagittal plane of 20 healthy overhead- and 20 nonoverhead-

117 throwing young adult athletes in supine. The authors concluded that

118 shortening of the PMm in the dominant shoulder of the overhead throwers

119 (mostly tennis and baseball players) was the most likely explanation for the

120 greater difference found between sides in the anterior position of the

121 acromion (McClain, et al., 2012). Kinematic studies showed that male

122 athletes of several overhead throwing sports have a more protracted

123 and anteriorly tilted scapular resting position in the dominant arm

124 comparatively to their non-dominant arm (Oyama, Myers, Wassinger, 125 Ricci, \& Lephart, 2008; Ribeiro \& Pascoal, 2013), or the dominant arm of 126 non-athletes (Ribeiro \& Pascoal, 2013). Although the primary goal of 
127 these investigations was not to study the association between soft

128 tissue adaptations and chronic overhead throwing, the scapular pattern

129 found has been related to a tight PMm (J. D. Borstad, 2006; J. D.

130 Borstad \& Ludewig, 2005). These researches seem to suggest the

131 existence of resting length adaptations of the PMm in response to

132 repetitive powerful scapular protraction movements during throwing,

133 however, without longitudinal studies a cause-effect relationship

134 cannot be established. Other musculoskeletal adaptations in the

135 dominant shoulder of overhead throwers may also explain some of the

136 findings in scapular position and orientation reported above, such as

137 posterior shoulder tightness (Laudner, Moline, \& Meister, 2010).

138 The few prospective studies that have examined changes in the

139 mechanical properties of human muscles after exposure to chronic

140 muscle actions similar to those used during throwing actions (i.e.,

141 stretch-shortening cycles), found an increased stiffness (more

142 resistance to passive stretching) of the muscle tissue \{Malisoux, 2006

143 \#11855;Fouré, Nordez, \& Cornu, 2012). Yet, the effects on muscles

144 resting length were not studied. Further research is warranted to

145 understand whether a change in PMm length and scapular orientation

146 is indeed related to an excessive active tension of the muscle in

147 shortening.

148 The PMm may also shorten secondary to conditions that

149 approximate its muscular attachments or reduce the range of its

150 operating length. In muscles immobilized in a shortened position, there

151 is evidence that muscle length and extensibility decreases, possibly 
152 due to a decline in the protein content and arrangement of the

153 connective tissues in the muscle belly (Gajdosik, 2001). With this in

154 mind, it is expected that local and regional biomechanical factors with

155 potential to decrease scapular upward rotation, external

156 rotation/retraction and posterior tilting relative to the thorax (e.g.,

157 strength imbalances of shoulder muscles or upper quadrant posture

158 and mobility) may predispose the PmM to adaptive shortening. Tsai et

159 al. (2003) observed that, after applying a fatigue protocol to the external

160 rotators of the dominant shoulder, the scapular resting posture of $\mathbf{3 0}$

161 asymptomatic subjects have changed slightly but significantly (up to

$162 \mathbf{4}^{\circ}$ ) to a more anteriorly tilted, internally rotated and downwardly rotated

163 position, a pattern that persisted during arm elevation. Even though

164 scapulothoracic or axioscapular muscles were not assessed in this

165 study, the authors recognized that the strength of the inferior trapezius

166 and serratus anterior muscles may have been affected by the fatigue

167 protocol and, in part, be responsible for the scapular kinematic

168 changes found (Tsai, et al., 2003). This possibility gives impetus to the

169 hypothesis that impaired strength of PMm antagonist muscles may

170 change scapular position and motion patterns and mediate its adaptive

171 shortening (Kendall, et al., 2005; Sahrmann, 2002). Research is needed

172 to confirm this hypothesis.

173 A shortened PMm is frequently assumed to be linked with

174 increased scapular protraction/tilting, forward head posture, and

175 thoracic kyphosis, plus impaired mobility of the upper body quadrant.

176 Findings from investigations conducted in asymptomatic subjects may 
177 provide support to the existence of such regional interrelationships.

178 Lee et al. (2015) found moderate to strong correlations between static

179 measurements of PMm length, forward scapular posture and thoracic

180 kyphosis $(r \geq .72, n=18)$. Others observed that simulating increased,

181 rigid thoracic kyphosis may increase up to $10^{\circ}$ the anterior tilting and

182 internal rotation of the scapula throughout different degrees of arm

183 elevation (Finley \& Lee, 2003; Kebaetse, McClure, \& Pratt, 1999), whilst

184 restricting full arm elevation capacity (Kebaetse, et al., 1999). Forward

185 head posture, either simulated or acquired, has been shown to slightly

186 but significantly restrict scapular posterior tilting (up to $3.5^{\circ}$ ) (Ludewig

187 \& Cook, 1996; Thigpen, et al., 2010), external rotation (up to $8^{\circ}$ )

188 (Thigpen, et al., 2010) and upward rotation (up to $5^{\circ}$ ) (Ludewig \& Cook, 189 1996; Thigpen, et al., 2010) during arm elevation. These investigations

190 may strengthen the idea that increased forward scapular posture,

191 forward head posture and thoracic kyphosis could create a propitious

192 environment to the adaptive shortening of the PMm; however, given the

193 cross-sectional nature of the studies or the absence of PMm length

194 measurements in data analyses, solid relationships are yet to be

195 established.

196

Association between adaptive shortening of the PMm and altered

198 scapular resting position and motion (scapular dyskinesis)

Although the relationship between PMm length and altered scapular

200 resting position and motion has been hypothesized for a long time, the

201 significant contributions to demonstrate its existence and magnitude were 
202 only made recently with the works of Borstad and Ludewig (2005) and

203 Borstad (2006). These authors divided a sample of asymptomatic adults in

204 two groups: one group with a relatively short PMm $(n=25)$ and the other

205 group with a relatively long PMm $(n=25)($ J. D. Borstad, 2006; J. D. Borstad

206 \& Ludewig, 2005). Then, they compared the 3-dimensional scapular

207 kinematics of the two groups at specific angles of arm elevation in the three

208 planes of orientation. With the subjects standing upright, significant

209 differences were found between groups, with the shorter PMm group

210 showing on average $\sim 8^{\circ}$ of more scapular internal rotation/protraction than

211 the other group. Furthermore, scapular internal rotation at rest was

212 significantly correlated $(r=0.39)$ with PMm length normalized to subjects'

213 height (J. D. Borstad, 2006). During arm elevation, the short PMm group

214 showed decreased external rotation/retraction (up to $10.5^{\circ}$ ) and posterior

215 tilting (up to $10.4^{\circ}$ ) of the scapula in any plane of orientation compared with

216 the longer PMm group (J. D. Borstad \& Ludewig, 2005). Despite the

217 widespread belief that a shortened PmM may contribute to scapular

218 depression or downward rotation, no association was found between

219 PMm length and these scapular movements (J. D. Borstad, 2006) nor

220 differences between short and long PMm subjects with regard to

221 scapular upward/downward rotation (J. D. Borstad \& Ludewig, 2005).

222

223

Association between PMm length/scapular dyskinesis, shoulder

224 pathomechanics, and upper quadrant pain syndromes

225 Studies comparing competitive overhead sports athletes with

226 and without shoulder pain and disability found a shorter PMm in those 
227 reporting shoulder pain (Harrington, Meisel, \& Tate, 2014; Reeser, et al.,

228 2010; Tate, et al., 2012). Given the cross-sectional nature of these

229 investigations, it is unclear whether PMm tightness could be a

230 contributory factor or a consequence of shoulder pain. Prospective

231 studies investigating risk factors for the development of shoulder

232 injuries in athletes might help clarifying this relationship, however, the

233 literature reveals contradictory findings. While some studies identified

234 significant contributions of scapular dyskinesis to subsequent

235 shoulder problems (Clarsen, Bahr, Andersson, Munk, \& Myklebust,

236 2014; Kawasaki, Yamakawa, Kaketa, Kobayashi, \& Kaneko, 2012;

237 McKenna, Straker, \& Smith, 2012), others challenge these results by

238 showing no association between scapular dyskinesis and the

239 development of shoulder pain (Myers, Oyama, \& Hibberd, 2013; F.

240 Struyf, et al., 2014). Different methods for screening scapular

241 (dys)function, type of sports, level of activity, instruments to evaluate

242 symptoms and disability, or unknown representative sample size may

243 explain part of the conflicting results. Moreover, the participation of

244 PMm tightness in scapular position and motion in these studies was

245 not clearly defined, except for the study of Struyf et al. (2014). Further

246 investigations are therefore required.

247 A recent systematic review of research investigating the

248 relationship between scapular orientation and kinematics in people

249 diagnosed with subacromial impingement syndrome (SIS), concluded

250 that although no definitive relationship could be established, a

251 decreased scapular retraction, posterior tilting and/or upward rotation 
252 may narrow the subacromial space and result in mechanical

253 impingement of the tissue, thereby regarded as a contributing factor for

254 developing or perpetuating SIS (Ratcliffe, et al., 2014). Studies included

255 in the review have suggested a tight PMm as a possible contributing

256 mechanism to the kinematic changes found in those subgroup of

257 patients with SIS (Hebert, Moffet, McFadyen, \& Dionne, 2002;

258 Lukasiewicz, McClure, Michener, Pratt, \& Sennett, 1999); however, the

259 PMm length was not assessed in those studies, which limits our

260 understanding of its presumed contribution to the condition. Further

261 research is needed to more definitively discern the role of PMm

262 tightness in subacromial narrowing, impingement, and sensitization of 263 subacromial tissues.

264 Symptoms related to scapular dyskinesis and PMm tightness may not

265 be restricted to the glenohumeral joint area. Parascapular and paracervical

266 complaints may also be present. Cleland et al. (2006) reported a

267 prevalence of $\mathbf{4 5} \%$ of restricted PMm length in a group of 22 patients

268 with mechanical neck pain. Shahidi et al. (2012) found a significantly

269 reduced PMm length bilaterally in a group of patients with chronic neck

270 pain $(n=19)$ compared to healthy subjects $(n=20)$. Others have

271 associated increased anterior tilting of the scapula with a tight PMm in

272 patients with whiplash-associated disorder $(n=23)$ (Helgadottir,

273 Kristjansson, Mottram, Karduna, \& Jonsson, 2011). Despite these

274 observations, the importance of PMm length to pain mechanism or

275 disability in these patients has not been established. Axioscapular

276 muscles have the dual role of orientating the scapula while 
277 simultaneously transferring forces between the upper limbs and the

278 axial skeleton, including the cervical spine. Given the alterations of

279 axioscapular motor control in response to pain experience in the neck

280 region (Christensen, Hirata, \& Graven-Nielsen, 2015), it seems plausible

281 that changes in PMm length could be a movement adaptation to pain.

282 Others believe that symptoms are likely related to an excessive effort of the

283 PMm antagonist muscles (e.g., upper and lower trapezius) to minimize the

284 impact of PMm tightness on shoulder position and motion during upper limb

285 activities (Burkhart, et al., 2003; Sahrmann, 2002; Weon, et al., 2010).

286 Further research is needed to clarify the role of PMm length in patients

287 with different types or presentation of painful neck disorders, as not all

288 patient groups may show a presumed shorter PMm or related scapular

289 kinematics (Helgadottir, et al., 2011; Nagai, et al., 2014).

\section{Brief summary}

The associations between PMm tightness, altered scapular position

293 and motion, shoulder movement dysfunction, abnormal stress in tissues and

294 pain are not unequivocal, but the growing evidence suggests that these

295 associations are not merely anecdotal. There are limitations on the

296 findings of studies that need to be addressed in the future. In

297 particular, valid and reliable measurements of PMm length ought to be

298 used (see discussion below), measures of PMm length and scapular

299 and upper quadrant kinematics need to be recorded simultaneously,

300 and the participation of PMm tightness in shoulder/neck pain

301 mechanisms must be demonstrated experimentally. The available 
302 research indicates that the evaluation of the PMm resting length and

303 extensibility is important to be considered in people presenting scapular

304 dyskinesis, particularly when showing increased scapular internal

305 rotation/protraction and anterior tilting. The presence of shoulder and/or

306 parascapular and paracervical pain should alert the clinician to assess PMm

307 tightness and scapular dyskinesis, specially when those are aggravated by

308 activities performed during or with arm elevation activities.

309

310 Clinical assessment of PMm tightness

311 No consensus exists about the best procedure(s) to assess PMm

312 tightness. Tight soft tissues are characterized by a decrease in length and a

313 greater resistance to stretching and motion. Thus, the assessment of PMm

314 tightness has been mostly based on the measurement of its length through

315 direct or indirect (i.e., through scapular position) methodologies. Table 1

316 compiles the measurement properties of these clinical measures. Strengths

317 and weaknesses of each methodology and recommendations for a better

318 assessment of PMm tightness considering the potential relationships with the

319 axial skeleton, its dominant effect in abnormal scapular position and motion,

320 and pain (if it exists) are discussed below.

321

322 Direct assessment of PMm length

323 Direct assessment of PMm length has been investigated in studies

324 conducted in both asymptomatic subjects and cadavers (J. D. Borstad,

325 2008). It can be performed by simply measuring in the standing upright

326 position the distance between the medial-inferior angle of the coracoid 
327 process and the inferior aspect of the 4th rib, laterally to the sternocostal

328 junction, with a caliper or a measuring tape (Table 1, Figure 2) (J. D.

329 Borstad, 2008). For clinical purposes, direct measurement of PMm length

330 should be normalized to a person's anthropometrics. Originally, body length

331 was used to normalize PMm length [Pectoralis Minor Index $(\mathrm{PMI})=\mathrm{PMm}$

332 length $(\mathrm{cm}) /$ subject height $(\mathrm{cm}) \times$ 100] (J. D. Borstad \& Ludewig, 2005), but

333 others have recently suggested to use the clavicle length instead (Tate, et

334 al., 2012). Which body reference to normalize PMm length provides the best

335 information for between-subject comparisons and clinical decision-making is

336 currently unknown and deserves further investigation.

337 The PMI has shown good to excellent intrarater reliability in patients

338 with SIS (symptomatic side) and good intrarater reliability in shoulders of

339 healthy subjects (J.-h. Lee, Cynn, Yoon, Ko, et al., 2015; Filip Struyf, et al.,

340 2014). Given the clinical belief that PMm tightness is involved in the

341 pathogenesis or perpetuation of shoulder/neck pain syndromes, the

342 evaluation of the clinimetric properties (e.g., sensitivity, specificity) of the

$343 \mathrm{PMI}$ is essential to understand its value in differentiating people with these

344 complaints. Judging by the small differences found between sides and

345 between people with and without shoulder pain, and the relatively wide

346 estimate of the minimal detectable change (Table 1) (Filip Struyf, et al.,

347 2014), we anticipate difficulties in establishing a robust criterion (cut-off

348 value) for diagnostic purposes. Still, a PMI value lower than 7.44 has been

349 considered suggestive of a shortened PMm (J. D. Borstad, 2008), which is

350 likely to affect the range and/or ease of retraction/external rotation and

351 posterior tilting motions of the scapula during arm elevation (J. D. Borstad \& 
352 Ludewig, 2005). Hence, this measurement appears to be valuable for

353 assisting in the diagnosis of scapular dyskinesis and clinical decision-making

354 in shoulder/neck pain syndromes.

355

356 Indirect assessment of PMm length

357 Many clinicians prefer assessing scapular position and motion and,

358 based on the outcome, inferring about the PMm length (W. Ben Kibler \&

359 Sciascia, 2010; W. B. Kibler, et al., 2002; Kluemper, Uhl, \& Hazelrigg, 2006;

360 McClain, et al., 2012; Roddey, Olson, \& Grant, 2002). Although this

361 practice has a sound scientific basis (J. D. Borstad, 2006; J. D. Borstad

362 \& Ludewig, 2005), the several clinical measurements listed in Table 1

363 should be used judiciously. Research has demonstrated questionable validity

364 (J. D. Borstad, 2006; Morais, 2009) and diagnostic value (J. S. Lewis \&

365 Valentine, 2007; J. Nijs, Roussel, Vermeulen, \& Souvereyns, 2005) of

366 several of those measurements, even if acceptable reliability and agreement

367 parameters were observed. For example, a forward shoulder/scapular

368 posture (FSP) is frequently attributed to a tight PMm (Kendall, et al., 2005;

369 W. Ben Kibler \& Sciascia, 2010; McClain, et al., 2012; Jo Nijs, Roussel,

370 Struyf, Mottram, \& Meeusen, 2007; Sahrmann, 2002; Wong, Coleman,

371 diPersia, Song, \& Wright, 2010). Yet, Borstad (2006) showed that when FSP

372 is measured in the supine position by the distance between the treatment

373 table and the acromion [also known as the PMm Length Test (J. S. Lewis \&

374 Valentine, 2007), see Table 1, or the scapular anterior tilting index (J.-H.

375 Lee, Cynn, Yoon, Choi, et al., 2015)], its outcome is poorly correlated with

376 a normalized PMm resting length (PMI). Hence, this measurement does not 
377 seem to guarantee a proper assessment of PMm length or tightness

378 although frequently used in clinical studies (Nagai, et al., 2014; Shahidi,

379 et al., 2012; F. Struyf, et al., 2014). A FSP may also be assessed in the

380 upright position to account for the natural effect of gravity on the alignment of

381 body parts. With the person standing against a wall, the examiner measures

382 the distance between the wall and the acromion through special levelled

383 metric rulers (Peterson, et al., 1997) (second indirect measurement shown

384 in Table 1 - linear approach). In recent studies conducted in

385 asymptomatic populations, this measurement has shown significant

386 associations with normalized PMm resting length (PMI) (J.-H. Lee,

387 Cynn, Yi, et al., 2015), posterior shoulder tightness (Laudner, Moline, \&

388 Meister, 2010; J.-H. Lee, Cynn, Yi, et al., 2015) and thoracic kyphosis

389 (J.-H. Lee, Cynn, Yi, et al., 2015). Despite these interesting findings,

390 from a clinical decision-making perspective, this measurement may not

391 be helpful to identify which particular biomechanical mechanism is

392 more likely to contribute to misalignment in a certain person and tailor

393 the intervention accordingly.

$394 \quad$ Other indirect methods with potential to determine PMm length

395 (Lynch, Thigpen, Mihalik, Prentice, \& Padua, 2010; Roddey, et al., 2002)

396 were originally designed to assess scapular position and displacement in the

397 frontal plane (DiVeta, Walker, \& Skibinski, 1990; Host, 1995; W. B. Kibler,

398 1998; Sobush, et al., 1996). We have grouped and designated them as

399 scapular protraction measurement because of their similar procedures (i.e.,

400 measurement of the distance between the thoracic spine and the scapula)

401 and theoretical framework. In general, these measurements have shown 
402 moderate to strong correlations with plane radiographs using the same

403 reference points and a reasonable reliability (Table 1). Yet, this may not

404 correspond to a true quantification of scapular position or orientation.

405 Preliminary findings from a sample of healthy young adults $(n=14)$ verified

406 that most of these measurements were more related to anthropometrics of

407 the upper body quadrant (e.g., thorax width or clavicle length) than to

408 scapular protraction (Morais, 2009). The risk of misinterpretation when using

409 them to assess scapular protraction is therefore high. One exception was

410 found for a similar method, the scapula index (SI) (J. D. Borstad, 2006). The

$411 \mathrm{SI}$ is the ratio between the distance from the sternal notch to the coracoid

412 process and the distance from the thoracic spine to the posterolateral angle

413 of the acromion, multiplied by 100 . These measurements showed

414 correlations with scapular internal rotation/protraction (J. D. Borstad, 2006;

415 Morais, 2009) and PMI (J. D. Borstad, 2006) up to 0.65 (Pearson's r),

416 suggesting that SI may be valuable in assessing scapular internal

417 rotation/protraction and PMm length (Table 1). Cut-off values have not been

418 defined yet, which limits its clinical usefulness.

419 The displacement of the inferior angle of the scapula from the

420 posterior thorax (or winging) is also referred to as an altered scapular pattern

421 associated to a tight PMm (Burkhart, et al., 2003; Lukasiewicz, et al., 1999;

422 Jo Nijs, et al., 2007; Sahrmann, 2002; Struyf, et al., 2011). Some relatively

423 simple measures can reliably quantify this displacement (Table 1, scapular

424 winging or tilting measurement) (Plafcan, Turczany, Guenin, Kegerreis, \&

425 Worrell, 1997; Weon, et al., 2011); however, it is uncertain whether this

426 displacement is actually related to PMm tightness. Impaired activity of the 
427 serratus anterior muscle can also cause scapular winging (Ludewig \& Cook,

428 2000; Weon, et al., 2011), which emphasizes the necessity to add further

429 data to the assessment of scapular position and motion in order to

430 differentiate the contributing mechanisms of scapular dyskinesis and

431 improve clinical decision-making, as we will discuss below.

432

433 Recommendations for the assessment of PMm tightness

434 Deciding whether PMm tightness exerts a dominant effect in scapular

435 dyskinesis and/or complaints is vital to effectively correct movement

436 impairment, reduce symptoms and obtain an optimal outcome. In this

437 sense, PMm tightness may be better assessed through a combination

438 of tests. Static assessment starts with the person standing in the

439 upright position. Observation of a more protracted scapula in the dominant

440 or symptomatic shoulder could be suggestive of a shortened PMm. This

441 rough estimation should be confirmed with a direct measurement of its

442 resting length (Figure 2), considering the aforementioned cut-off value.

443 Palpation of the muscle belly could be helpful to assess potential changes in

444 tissue compliance (e.g., tightness or stiffness); however, there is still no

445 scientific evidence of its clinical value in the assessment of PMm.

446 Static assessment of the PMm length should be complemented with

447 the assessment of scapular mobility. Performing manual retraction and

448 posterior tilting of the scapula may help estimate PMm extensibility, inform

449 the therapist about its passive resistance to scapular motion and highlight the

450 compensatory movements occurring in the axial skeleton (e.g., elevation of

451 the ribs or thoracic extension when the PMm is excessively tight - Figure 3). 
452 Assessment of scapular position and motion during arm elevation is

453 also important to be evaluated to verify if a scapular pattern consistent

454 with a shortened PMm exists (J. D. Borstad \& Ludewig, 2005). However,

455 differentiating between PMm tightness and impaired function of its

456 antagonist muscles in the mechanism of increased scapular protraction

457 and anterior tilting and/or pain during arm elevation is challenging without

458 proper instrumentation, such as electromyograms or motion tracking devices

459 (Uhl, Kibler, Gecewich, \& Tripp, 2009). Furthermore, both muscle

460 mechanisms might be associated. The current alternative for clinical

461 practice consists of performing active retraction of the scapulae (J. Nijs, et

462 al., 2005) and manual muscle testing of the serratus anterior and the lower

463 portion of the trapezius (P. McClure, Greenberg, \& Kareha, 2012) to check

464 for impairments in muscle strength, and manual redirection of the scapula to

465 test for changes in symptoms (Rabin, Irrgang, Fitzgerald, \& Eubanks, 2006).

466 Given that the latter procedure is not specifically designed to test the

467 influence of PMm tightness but rather the general contribution of the scapula

468 in the pathogenesis of the pain, a strong resistance felt during manual

469 correction of anterior tilting, retraction and upward rotation of the scapula

470 may suggest PMm tightness. Studies are needed to determine the

471 relationship between PMm length and pain during movement in pain

472 provocative positions.

473 As early discussed, increased forward head posture and thoracic

474 kyphosis may also alter scapular posture and restrict motion in a similar

475 pattern to that of a shortened PMm. Hence, the examination of posture and

476 mobility of the head, cervical and thoracic spines should be conducted along 
477 with scapular evaluation to improve clinical decision. This can be verified by

478 simply repositioning the axial skeleton to the midline, in the upright standing

479 position, and then assess changes in scapular position and motion and in

480 symptoms, and vice-versa (Figures 3).

481

482 Treatment approaches to increase PMm length

483 Stretching techniques are a common approach to improve

484 muscles length and extensibility (Gajdosik, 2001). To lengthen the

485 PMm, the muscular insertion in the coracoid process should be moved

486 away from the attachments in the thorax $\left(3^{\text {rd }}, 4^{\text {th }}\right.$ and $5^{\text {th }}$ ribs $)$. A wide

487 variety of stretching techniques and positions have been proposed, taking

488 into account several clinical factors, such as the rehabilitation stage, the

489 presence or absence of pain, the importance of PMm tightness in movement

490 dysfunction, or the need for a simple technique to be performed by the

491 patient (self-stretching) (Bang \& Deyle, 2000; John D. Borstad \& Ludewig,

492 2006; Kendall, et al., 2005; Kisner \& Colby, 2007; Lawson, Hung, Ko, \&

493 Laframboise, 2011; T. S. Lee, et al., 2007; Lynch, et al., 2010; Wang,

494 McClure, Pratt, \& Nobilini, 1999; Wong, et al., 2010). A short synthesis of the

495 available stretching techniques is provided as supplementary material. Small

496 variations have also been proposed (Burkhart, et al.; Caldwell, Sahrmann, \&

497 Van Dillen, 2007; Kluemper, et al., 2006; P. W. McClure, Bialker, Neff,

498 Williams, \& Karduna, 2004; Roddey, et al., 2002; Sahrmann, 2002). The

499 corner or doorway stretch (passive horizontal abduction with the shoulder at

$50090^{\circ}$ of abduction and external rotation) is one of the most frequently used

501 exercises to stretch the PMm in preventive and rehabilitation programs 
502 (Bang \& Deyle, 2000; W. Ben Kibler, et al., 2013; Ludewig \& Borstad, 2003;

503 P. W. McClure, et al., 2004; Wang, et al., 1999). It has the advantage of

504 being self-administered and offering great potential to lengthen the PMm

505 (John D. Borstad \& Ludewig, 2006). However, patients with shoulder

506 complaints, particularly those with subacromial pain syndrome, may

507 experience pain intensification in this position (Figure 1). Moreover,

508 increasing glenohumeral horizontal abduction may furthermore strain

509 the anteroinferior capsoligamentous complex of the glenohumeral joint

510 and aggravate functional imbalances between the anterior and

511 posterior sides of the shoulder, a known contributing factor for

512 developing or worsening shoulder pain and disability in overhead

513 throwing athletes (Borsa, Laudner, \& Sauers, 2008). In such cases,

514 PMm stretch can be attained by the application of a posterior force to

515 the coracoid process into retraction within a pain-free or tolerable

516 glenohumeral range of motion (John D. Borstad \& Ludewig, 2006;

517 Burkhart, et al., 2003; Caldwell, et al., 2007; Kisner \& Colby, 2007;

518 Kluemper, et al., 2006; Sahrmann, 2002). Studies conducted in

519 asymptomatic subjects (John D. Borstad \& Ludewig, 2006) and

520 cadavers (Muraki, et al., 2009) showed that this manual action indeed

521 lengthens the PMm significantly, nevertheless its magnitude may be

522 limited if not combined with arm elevation (John D. Borstad \& Ludewig,

523 2006; Muraki, et al., 2009). Thus, when deemed appropriated,

524 glenohumeral motion should be encouraged. During passive elevation

525 of the arm, the scapula naturally undergoes upward rotation, posterior

526 tilting and external rotation/retraction (Ebaugh, McClure, \& Karduna, 
527 2005), which moves the PMm insertion on the coracoid process

528 posteriorly and superiorly relative to the thorax. Up to $150^{\circ}$ of passive

529 arm elevation lengthens the PMm gradually, resulting in a mean change

530 of $50 \%$ compared with its resting length (Muraki, et al., 2009). This

531 value, however, was observed in a cadaveric model, which cannot be

532 extrapolated to living subjects. The activity of the serratus anterior and

533 lower trapezius increases the magnitude of scapular motions during

534 arm elevation (Ebaugh, et al., 2005), hence, complementing PMm

535 stretching with the activity of these muscles seems essential to

536 magnify its lengthening. This hypothesis has gained support recently.

537 Lee et al.(2015) demonstrated that combining PMm stretching with a

538 posterior tilting exercise increased PMm resting length (PMI) and

539 improved upward rotation and anterior/posterior tilting alignment of the

540 scapula in a group of asymptomatic subjects with a short PMm $(n=15)$.

$541 \quad$ Soft tissue mobilization (Williams, Laudner, \& McLoda, 2013;

542 Wong, et al., 2010), corrective braces (J.-h. Lee, Cynn, Yoon, Ko, et al.,

543 2015), and scapular kinesiology taping (Han, Lee, \& Yoon, 2015) have

544 been suggested as adjuvant or alternative techniques to stretching in

545 the management of PMm tightness and forward shoulder posture.

546 Albeit previous studies have shown that manual soft tissue

547 mobilizations may influence the biomechanical properties of muscle

548 tissues (Eriksson Crommert, Lacourpaille, Heales, Tucker, \& Hug,

549 2015), only the latter appear to be beneficial at increasing PMm length

550 and improve scapulothoracic alignment (Han, et al., 2015; J.-h. Lee,

551 Cynn, Yoon, Ko, et al., 2015). Further studies are necessary to evaluate 
552 the potential advantages of combining treatment modalities in the

553 management of postural and movement impairments of the shoulder

554 and upper body quadrant related to muscle tightness.

555

556

PMm stretching in a rehabilitation approach to optimize the kinematic

557 chain of arm elevation

$558 \quad$ Interventions aiming to improve PMm length and extensibility at rest

559 and during arm elevation should also consider the influence of the position

560 and motion of the head, cervical and thoracic spines and rib cage. Good

561 postural alignment and mobility of the axial skeleton may facilitate a normal

562 scapular position and motion during arm elevation (Finley \& Lee, 2003;

563 Kebaetse, et al., 1999; Ludewig \& Cook, 1996; Thigpen, et al., 2010; Weon,

564 et al., 2010) and, possibly, PMm stretching. Given this, some authors have

565 included thoracic spine extension in PMm stretching, but few have accounted

566 for head posture or arm position (John D. Borstad \& Ludewig, 2006;

567 Burkhart, et al., 2003; Kluemper, et al., 2006; Lynch, et al., 2010). Others

568 have suggested moving both points of attachment of the PMm in the

569 opposed direction through arm and trunk dissociation (Bang \& Deyle, 2000;

570 Lawson, et al., 2011; Wong, et al., 2010) or through the assistance of

571 thoracic movement and breathing patterns (John D. Borstad \& Ludewig,

572 2006; Kisner \& Colby, 2007). However, none of the techniques combines all

573 these components together.

574 To efficiently act on the kinesiopathologic chain provided in Figure 1,

575 optimize PMm lengthening and facilitate the restoration of a normal or further

576 adaptable scapular motion, the progressive alignment of the axial skeleton 
577 with PMm stretching seems mandatory. This progressive alignment is better

578 controlled with the person in supine, starting with arms alongside the trunk.

579 The sagittal alignment of the axial skeleton and forward head through

580 head retraction and lengthening of the cervical and thoracic spines

581 tensions the scaleni muscles and extends the thoracic spine. This

582 elevates the upper ribs (Figures 3 and 4), which may reduce the

583 lengthening capacity of the PMm. Thus, deep progressive expirations

584 should be encouraged to move away the thoracic insertions of the PMm from

585 that of the coracoid process while keeping spinal alignment (Figures 4 and

586 5). A light overpressure can be applied on the ribs at the end of expiration to

587 facilitate this movement. Since PMm assists in inspiration (Kendall, et al.,

588 2005; Palastanga, Field, \& Soames, 2002), upper thoracic inspiration should

589 be avoided to actively limit shortening of its muscle fibers. The diaphragmatic

590 breathing should be encouraged instead (Figure 4). The manual contact of

591 the clinician must be different in male and female patients to account for the

592 difference in their physiognomy (specifically in breast sizes). In female

593 patients, the proximal hand of the clinician should address the thoracic

594 insertions of the PMm indirectly, either through the sternum or the lower

595 adjacent ribs (Figure 4, frame 3; and Figure 5, frames 2 and 4). The other

596 hand should apply a posterior and superior force to the coracoid process to

597 further stretch the PMm (Figures 4 and 5). These actions offer a more

598 balanced stretching between PMm attachments, a more comfortable feeling

599 to patients, and a safer procedure to be performed in the early stages of

600 rehabilitation after a shoulder injury. 
The addition of the shoulder abduction component should be slow and

602 gradual (Figure 5). The starting range and increment rate of shoulder

603 abduction depend on the previous clinical assessment (e.g., pain elicited at a

604 specific range of motion). A progressive increment of $10^{\circ}$ is usually safe and

605 allows an efficient management of the compensatory movements that may

606 occur during shoulder abduction, such as the scapula moving into protraction

607 (or less retraction) or elevation of the ribs. The patient must keep the scapula

608 attached to the surface of the table using PMm antagonist muscles (e.g.,

609 lower trapezius), thereby facilitating external rotation, posterior tilting and

610 upward rotation (Ebaugh, et al., 2005). If difficult, the clinician can further

611 perform the contract-relax technique of the PMm to facilitate its lengthening

612 and the activity of its antagonist muscles. As the arm is being abducted,

613 particularly after the $90^{\circ}$, the trunk will naturally follow contralateral side

614 flexion, ipsilateral axial rotation, and extension (Fayad, et al., 2008). The

615 tighter the PMm is, the sooner the thorax is expected to follow arm

616 movement. To obtain a full distance between PMm attachments (full

617 stretching), these thoracic movements should be stabilized. This can be

618 performed by either applying an external force on the rib cage, as previously

619 described, or actively controlling these movements using the contraction of

620 the core muscles of the trunk (Figures 4 and 5). To ensure a proper

621 alignment of the thoracic spine with the cervical spine and the rib cage

622 throughout the stretching maneuver, a manual correction should

623 periodically complement the visual inspection (Figure 6). The therapist

624 places his or her hand between the table and the mid-thoracic spine, 
625 with the spinous processes between the $3^{\text {rd }}$ and $4^{\text {th }}$ fingers. With the

626 patient's body in a restfully position on the therapist's hand and arm

627 (wrist in the neutral position), the therapist uses the spinous processes

628 as fulcrum and through wrist movements performs contralateral gliding

629 and rotation and ipsilateral side-flexion of the vertebrae to the midline.

630 Then, the therapist slides his or her hand up to the occiput using a

631 posterior movement of his/her body, manually lengthening the spine.

632 The other hand can control rib cage movements and perform lateral

633 alignment of the cervical spine to the midline and head retraction as the

634 lower hand reaches the occiput.

635 This rehabilitation approach has the advantage of stretching the PMm

636 through passive (gravity and/or the manual action of the therapist) and active

637 (PMm antagonist muscles) forces throughout the range of motion of arm

638 elevation while considering regional interrelationships with the axial skeleton.

639 Muscle activity and motor control are encouraged, possibly influencing

640 scapular orientation and motion in a greater extent than stretching alone (J.-

641 H. Lee, Cynn, Yoon, Choi, et al., 2015; J.-h. Lee, Cynn, Yoon, Ko, et al.,

642 2015; Wang, et al., 1999; Williams, et al., 2013), likely reducing the

643 rehabilitation period. Research is needed to document the efficacy of this

644 approach.

645

646 Dosage

$647 \quad$ The efficacy of stretching techniques depends on the force and

648 duration (dosage) being applied. However, the best dosage for an effective

649 stretch has not been determined yet (Weppler \& Magnusson, 2010). A 
650 shorter stretching duration may reduce the perception of pain or increase

651 tolerance of the connective tissue to lengthening so the muscle can stretch

652 further (Weppler \& Magnusson, 2010). Sometimes this might be sufficient to

653 facilitate the achievement of other rehabilitation purposes deemed more

654 important in a particular case (e.g., strengthening shoulder external rotator

655 muscles). However, if limitations of the shoulder function are closely related

656 to a tight PMm, a longer stretching duration is required. A total duration of 1

657 to 10 minutes of PMm stretching has been suggested (Bang \& Deyle, 2000;

658 Kluemper, et al., 2006; Ludewig \& Borstad, 2003; Lynch, et al., 2010; P. W.

659 McClure, et al., 2004; Roddey, et al., 2002; Wang, et al., 1999; Wong, et al.,

660 2010). Nevertheless, a minimum of 10 minutes per session appears to be

661 necessary to achieve a higher improvement in muscle flexibility and passive

662 stiffness over time, probably due to a more permanent deformation of the

663 connective tissue (Guissard \& Duchateau, 2004). To perform the stretching

664 technique throughout arm elevation, as described above, approximately 15-

66520 minutes are required.

666 The lengthening capacity of a muscle also depends greatly on the

667 force being applied (Weppler \& Magnusson, 2010). Nevertheless, this has

668 been poorly controlled in studies investigating the effects of stretching

669 techniques in PMm length (John D. Borstad \& Ludewig, 2006; J.-H. Lee,

670 Cynn, Yoon, Choi, et al., 2015; J.-h. Lee, Cynn, Yoon, Ko, et al., 2015;

671 Muraki, et al., 2009) and in scapular position and motion (J.-H. Lee, Cynn,

672 Yoon, Choi, et al., 2015; J.-h. Lee, Cynn, Yoon, Ko, et al., 2015; Williams, et

673 al., 2013). In order to understand which technique(s) might stretch the PMm 
674 in a greater extent, this parameter should also be considered in future

675 research.

676

677 Summary

678 The PMm may adaptively tighten when chronically exposed to

679 maintained postures and repetitive movements involving scapular protraction

680 and anterior tilting. Such tightness has been associated with altered

681 scapular position and motion (scapular dyskinesis) and be the cause or

682 the consequence of shoulder and/or neck pain syndromes. Clinical

683 assessment of PMm tightness is mostly based on the measurement of PMm

684 length through direct or indirect methodologies. However, given the possible

685 interaction between PMm tightness and other biomechanical mechanisms

686 and components of the upper body quadrant, PMm length should be

687 assessed along with the examination of scapular mobility, muscle strength of

688 its antagonist muscles, and posture and mobility of the head, cervical and

689 thoracic spines. Several stretching techniques have been proposed to

690 improve PMm length and extensibility; however, most of them do not account

691 for the influence of posture and mobility of the upper body quadrant on PMm

692 lengthening capacity. Further research is necessary to confirm the value of a

693 comprehensive assessment of PMm tightness, as presented in this

694 manuscript, and to identify which stretching technique(s) is/are more likely to

695 induce greater changes in PMm length and in scapular position and motion

696 over time.

697

698 References 
699 Bang, M. D., \& Deyle, G. D. (2000). Comparison of supervised exercise with and without manual physical therapy for patients with shoulder

701 impingement syndrome. Journal of Orthopaedic and Sports Physical

702 Therapy, 30, 126-137.

703 Borsa, P. A., Laudner, K. G., \& Sauers, E. L. (2008). Mobility and stability 704 adaptations in the shoulder of the overhead athlete: a theoretical and 705 evidence-based perspective. Sports Medicine, 38, 17-36.

706 Borstad, J. D. (2006). Resting position variables at the shoulder: evidence to 707 support a posture-impairment association. Physical Therapy, 86, 549557.

709 Borstad, J. D. (2008). Measurement of pectoralis minor muscle length:

710 validation and clinical application. Journal of Orthopaedic and Sports Physical Therapy, 38, 169-174.

712 Borstad, J. D., \& Ludewig, P. M. (2005). The effect of long versus short pectoralis minor resting length on scapular kinematics in healthy

714 individuals. Journal of Orthopaedic and Sports Physical Therapy, 35, 227-238.

716 Borstad, J. D., \& Ludewig, P. M. (2006). Comparison of three stretches for 717 the pectoralis minor muscle. Journal of Shoulder and Elbow Surgery, $718 \quad 15,324-330$.

719 Burkhart, S. S., Morgan, C. D., \& Kibler, W. B. (2003). The disabled throwing 720 shoulder: spectrum of pathology Part III: The SICK scapula, scapular 721 dyskinesis, the kinetic chain, and rehabilitation. Arthroscopy, 19, 641722 661. 
723 Caldwell, C., Sahrmann, S., \& Van Dillen, L. (2007). Use of a movement system impairment diagnosis for physical therapy in the management of a patient with shoulder pain. Journal of Orthopaedic and Sports Physical Therapy, 37, 551-563.

727

Christensen, S. W., Hirata, R. P., \& Graven-Nielsen, T. (2015). The Effect of Experimental Neck Pain on Pressure Pain Sensitivity and Axioscapular Motor Control. The Journal of Pain, 16, 367-379.

730 Clarsen, B., Bahr, R., Andersson, S. H., Munk, R., \& Myklebust, G. (2014). Reduced glenohumeral rotation, external rotation weakness and scapular dyskinesis are risk factors for shoulder injuries among elite male handball players: a prospective cohort study. British Journal of

735 Cleland, J. A., Childs, J. D., Fritz, J. M., \& Whitman, J. M. (2006). Interrater reliability of the history and physical examination in patients with mechanical neck pain. Archives of Physical Medicine and Rehabilitation, 87, 1388-1395.

739 Cools, A. M., Johansson, F. R., Cambier, D. C., Velde, A. V., Palmans, T., \& 740 Witvrouw, E. E. (2010). Descriptive profile of scapulothoracic position, 741 strength and flexibility variables in adolescent elite tennis players. 742 British Journal of Sports Medicine, 44, 678-684.

743 DiVeta, J., Walker, M. L., \& Skibinski, B. (1990). Relationship between 744 performance of selected scapular muscles and scapular abduction in 745 standing subjects. Physical Therapy, 70, 470-476; discussion 476746 479. 
747 Ebaugh, D. D., McClure, P. W., \& Karduna, A. R. (2005). Three-dimensional 748 scapulothoracic motion during active and passive arm elevation. Clinical Biomechanics, 20, 700-709.

750 Eriksson Crommert, M., Lacourpaille, L., Heales, L. J., Tucker, K., \& Hug, F. 751 (2015). Massage induces an immediate, albeit short-term, reduction in muscle stiffness. Scandinavian Journal of Medicine and Science in Sports, n/a-n/a.

754 Fayad, F., Hanneton, S., Lefevre-Colau, M.-M., Poiraudeau, S., Revel, M., \& Roby-Brami, A. (2008). The trunk as a part of the kinematic chain for arm elevation in healthy subjects and in patients with frozen shoulder. Brain Research, 1191, 107-115.

758 Finley, M. A., \& Lee, R. Y. (2003). Effect of sitting posture on 3-dimensional 759 scapular kinematics measured by skin-mounted electromagnetic tracking sensors. Archives of Physical Medicine and Rehabilitation, 84, 563-568.

762 Fouré, A., Nordez, A., \& Cornu, C. (2012). Effects of plyometric training on 763 passive stiffness of gastrocnemii muscles and Achilles tendon. European Journal of Applied Physiology, 112, 2849-2857.

765 Gajdosik, R. L. (2001). Passive extensibility of skeletal muscle: review of the 766 literature with clinical implications. Clinical Biomechanics, 16, 87-101.

767 Guissard, N., \& Duchateau, J. (2004). Effect of static stretch training on 768 neural and mechanical properties of the human plantar-flexor muscles. Muscle and Nerve, 29, 248-255.

770 Han, J.-T., Lee, J.-H., \& Yoon, C.-H. (2015). The mechanical effect of 771 kinesiology tape on rounded shoulder posture in seated male workers: 
a single-blinded randomized controlled pilot study. Physiotherapy Theory and Practice, 31, 120-125.

774 Harrington, S., Meisel, C., \& Tate, A. (2014). A cross-sectional study

775 examining shoulder pain and disability in Division I female swimmers.

$776 \quad J$ Sport Rehabil, 23, 65-75.

777 Hebert, L. J., Moffet, H., McFadyen, B. J., \& Dionne, C. E. (2002). Scapular

778 behavior in shoulder impingement syndrome. Archives of Physical

$779 \quad$ Medicine and Rehabilitation, 83, 60-69.

780 Helgadottir, H., Kristjansson, E., Mottram, S., Karduna, A., \& Jonsson, H., Jr.

781 (2011). Altered alignment of the shoulder girdle and cervical spine in

782 patients with insidious onset neck pain and whiplash-associated

783 disorder. Journal of Applied Biomechanics, 27, 181-191.

784 Host, H. H. (1995). Scapular taping in the treatment of anterior shoulder

785 impingement. Physical Therapy, 75, 803-812.

786 Kawasaki, T., Yamakawa, J., Kaketa, T., Kobayashi, H., \& Kaneko, K.

787 (2012). Does scapular dyskinesis affect top rugby players during a

788 game season? Journal of Shoulder and Elbow Surgery, 21, 709-714.

789 Kebaetse, M., McClure, P., \& Pratt, N. A. (1999). Thoracic position effect on

790 shoulder range of motion, strength, and three-dimensional scapular

$791 \quad$ kinematics. Archives of Physical Medicine and Rehabilitation, 80, 945-

792950.

793 Kendall, F. P., McCreary, E. K., Provance, P. G., Rodgers, M. M., \& Romani, 794 W. A. (2005). Muscles: Testing and Function with Posture and Pain

795 (5th ed ed.). Baltimore, MD: Lippincott, Williams, \& Wilkins. 
796 Kibler, W. B. (1998). The role of the scapula in athletic shoulder function. American Journal of Sports Medicine, 26, 325-337.

798 Kibler, W. B., Kuhn, J. E., Wilk, K., Sciascia, A., Moore, S., Laudner, K., 799 Ellenbecker, T., Thigpen, C., \& Uhl, T. (2013). The Disabled Throwing 800 Shoulder: Spectrum of Pathology-10-Year Update. Arthroscopy, 29, $801 \quad$ 141-161.e126.

802 Kibler, W. B., \& Sciascia, A. (2010). Current concepts: scapular dyskinesis. 803 British Journal of Sports Medicine, 44, 300-305.

804 Kibler, W. B., Sciascia, A., \& Wilkes, T. (2012). Scapular Dyskinesis and Its 805 Relation to Shoulder Injury. Journal of the American Academy of $806 \quad$ Orthopaedic Surgeons, 20, 364-372.

807 Kibler, W. B., Uhl, T. L., Maddux, J. W., Brooks, P. V., Zeller, B., \& McMullen, 808 J. (2002). Qualitative clinical evaluation of scapular dysfunction: a 809 reliability study. Journal of Shoulder and Elbow Surgery, 11, 550-556.

810 Kisner, C., \& Colby, L. A. (2007). Therapeutic Exercise: Foundations and 811 Techniques (5th ed ed.). Philadelphia, PA: F.A. Davis.

812 Kluemper, M., Uhl, T., \& Hazelrigg, H. (2006). Effect of Stretching and 813 Strengthening Shoulder Muscles on Forward Shoulder Posture in 814 Competitive Swimmers. Journal of Sports Rehabilitation, 15, 5-70.

815 Laudner, K. G., Moline, M. T., \& Meister, K. (2010). The Relationship $816 \quad$ Between Forward Scapular Posture and Posterior Shoulder Tightness 817 Among Baseball Players. The American Journal of Sports Medicine, $818 \quad 38,2106-2112$.

819 Lawson, G. E., Hung, L. Y., Ko, G. D., \& Laframboise, M. A. (2011). A case 820 of pseudo-angina pectoris from a pectoralis minor trigger point caused 
by cross-country skiing. Journal of Chiropractic Medicine, 10, 173-

822 178.

823 Lee, J.-H., Cynn, H.-s., Yi, C.-H., Kwon, O.-y., \& Yoon, T.-L. (2015).

824 Predictor variables for forward scapular posture including posterior 825 shoulder tightness. Journal of Bodywork and Movement Therapies, $826 \quad 19,253-260$.

827 Lee, J.-H., Cynn, H.-S., Yoon, T.-L., Choi, S.-A., Choi, W.-J., Choi, B.-S., \& 828 Ko, C.-H. (2015). Comparison of scapular posterior tilting exercise alone and scapular posterior tilting exercise after pectoralis minor stretching on scapular alignment and scapular upward rotators activity 831 in subjects with short pectoralis minor. Physical Therapy in Sport, 16, 832 255-261.

833 Lee, J.-h., Cynn, H.-s., Yoon, T.-I., Ko, C.-h., Choi, W.-j., Choi, S.-a., \& Choi, 834 B.-s. (2015). The effect of scapular posterior tilt exercise, pectoralis 835 minor stretching, and shoulder brace on scapular alignment and 836 muscles activity in subjects with round-shoulder posture. Journal of 837 Electromyography and Kinesiology, 25, 107-114.

838 Lee, T. S., Kilbreath, S. L., Refshauge, K. M., Pendlebury, S. C., Beith, J. M., 839 \& Lee, M. J. (2007). Pectoral stretching program for women 840 undergoing radiotherapy for breast cancer. Breast Cancer Research $841 \quad$ and Treatment, 102, 313-321.

842 Lewis, J. S. (2011). Subacromial impingement syndrome: a musculoskeletal $843 \quad$ condition or a clinical illusion? Physical Therapy Reviews, 16, 388844398 
845 Lewis, J. S., \& Valentine, R. E. (2007). The pectoralis minor length test: a 846 study of the intra-rater reliability and diagnostic accuracy in subjects

847 with and without shoulder symptoms. BMC Musculoskeletal Disorders, $848 \quad 8,64$.

849 Ludewig, P. M., \& Borstad, J. D. (2003). Effects of a home exercise

850 programme on shoulder pain and functional status in construction

$851 \quad$ workers. Occupational and Environmental Medicine, 60, 841-849.

852 Ludewig, P. M., \& Cook, T. M. (1996). The effect of head position on

853 scapular orientation and muscle activity during shoulder elevation.

$854 \quad$ Journal of Occupational Rehabilitation, 6, 147-158-158.

855 Ludewig, P. M., \& Cook, T. M. (2000). Alterations in shoulder kinematics and 856 associated muscle activity in people with symptoms of shoulder 857 impingement. Physical Therapy, 80, 276-291.

858 Ludewig, P. M., Lawrence, R. L., \& Braman, J. P. (2013). What's in a Name?

$859 \quad$ Using Movement System Diagnoses Versus Pathoanatomic

860 Diagnoses. Journal of Orthopaedic and Sports Physical Therapy, 43, $861 \quad 280-283$.

862 Ludewig, P. M., \& Reynolds, J. F. (2009). The Association of Scapular

863 Kinematics and Glenohumeral Joint Pathologies. Journal of

864 Orthopaedic and Sports Physical Therapy, 29, 90-104.

865 Lukasiewicz, A. C., McClure, P., Michener, L., Pratt, N., \& Sennett, B. (1999).

866 Comparison of 3-dimensional scapular position and orientation

867 between subjects with and without shoulder impingement. Journal of

868 Orthopaedic and Sports Physical Therapy, 29, 574-583. 
869 Lynch, S. S., Thigpen, C. A., Mihalik, J. P., Prentice, W. E., \& Padua, D.

870 (2010). The effects of an exercise intervention on forward head and

871 rounded shoulder postures in elite swimmers. British Journal of Sports

$872 \quad$ Medicine, 44, 376-381.

873 McClain, M., Tucker, W. S., \& Hornor, S. D. (2012). Comparison of Scapular

874 Position in Overhead-and Nonoverhead-Throwing Athletes Using the

875 Pectoralis Minor Length Test. Athletic Training \& Sports Health Care,

$876 \quad 4,45-48$.

877 McClure, P., Greenberg, E., \& Kareha, S. (2012). Evaluation and

878 management of scapular dysfunction. Sports Med Arthroc Rev, 20,

$879 \quad 39-48$

880 McClure, P. W., Bialker, J., Neff, N., Williams, G., \& Karduna, A. (2004).

$881 \quad$ Shoulder function and 3-dimensional kinematics in people with

882 shoulder impingement syndrome before and after a 6-week exercise

$883 \quad$ program. Physical Therapy, 84, 832-848.

884 McKenna, L., Straker, L., \& Smith, A. (2012). Can scapular and humeral

885 head position predict shoulder pain in adolescent swimmers and non-

$886 \quad$ swimmers? Journal of Sports Sciences, 30, 1767-1776.

887 Morais, N. V. (2009). Scapular Resting Position as a Clinical Parameter:

888 discussion about validity and interpretation of clinical assessment

889 tests. . Technical University of Lisbon. Faculty of Human Kinetics,

$890 \quad$ Lisbon.

891 Muraki, T., Aoki, M., Izumi, T., Fujii, M., Hidaka, E., \& Miyamoto, S. (2009).

892 Lengthening of the Pectoralis Minor Muscle During Passive Shoulder 
895 Myers, J. B., Oyama, S., \& Hibberd, E. E. (2013). Scapular dysfunction in

896 high school baseball players sustaining throwing-related upper

897 extremity injury: a prospective study. Journal of Shoulder and Elbow

$898 \quad$ Surgery, 22, 1154-1159.

899 Nagai, T., Abt, J. P., Sell, T. C., Clark, N. C., Smalley, B. W., Wirt, M. D., \&

900 Lephart, S. M. (2014). Neck proprioception, strength, flexibility, and

901 posture in pilots with and without neck pain history. Aviation Space

902 and Environmental Medicine, 85, 529-535.

903 Nijs, J., Roussel, N., Struyf, F., Mottram, S., \& Meeusen, R. (2007). Clinical

904 assessment of scapular positioning in patients with shoulder pain:

905 state of the art. Journal of Manipulative and Physiological

906 Therapeutics, 30, 69-75.

907 Nijs, J., Roussel, N., Vermeulen, K., \& Souvereyns, G. (2005). Scapular

908 positioning in patients with shoulder pain: a study examining the

909 reliability and clinical importance of 3 clinical tests. Archives of

$910 \quad$ Physical Medicine and Rehabilitation, 86, 1349-1355.

911 Novak, C. B., \& Mackinnon, S. E. (1997). Repetitive use and static postures:

912 A source of nerve compression and pain. Journal of Hand Therapy,

$913 \quad 10,151-159$.

914 Oyama, S., Myers, J. B., Wassinger, C. A., Ricci, R. D., \& Lephart, S. M.

915 (2008). Asymmetric Resting Scapular Posture in Healthy Overhead

916 Athletes. Journal of Athletic Training, 43, 565-570. 
917 Palastanga, N., Field, D., \& Soames, R. (2002). Anatomy and Human

918 Movement. Structure and Function (4th ed. ed.). Edinburgh:

$919 \quad$ Butterworth-Heinemann.

920 Peterson, D. E., Blankenship, K. R., Robb, J. B., Walker, M. J., Bryan, J. M.,

921 Stetts, D. M., Mincey, L. M., \& Simmons, G. E. (1997). Investigation of

922 the validity and reliability of four objective techniques for measuring

923 forward shoulder posture. Journal of Orthopaedic and Sports Physical

$924 \quad$ Therapy, 25, 34-42.

925 Plafcan, D. M., Turczany, P. J., Guenin, B. A., Kegerreis, S., \& Worrell, T. W.

926 (1997). An objective measurement technique for posterior scapular

927 displacement. Journal of Orthopaedic and Sports Physical Therapy,

$928 \quad 25,336-341$.

929 Rabin, A., Irrgang, J. J., Fitzgerald, G. K., \& Eubanks, A. (2006). The

930 intertester reliability of the Scapular Assistance Test. Journal of

$931 \quad$ Orthopaedic and Sports Physical Therapy, 36, 653-660.

932 Ratcliffe, E., Pickering, S., McLean, S., \& Lewis, J. (2014). Is there a

933 relationship between subacromial impingement syndrome and

934 scapular orientation? A systematic review. British Journal of Sports

$935 \quad$ Medicine, 48, 1251-1256.

936 Reeser, J. C., Joy, E. A., Porucznik, C. A., Berg, R. L., Colliver, E. B., \&

937 Willick, S. E. (2010). Risk Factors for Volleyball-Related Shoulder

$938 \quad$ Pain and Dysfunction. $P M \& R, 2,27-36$

939 Ribeiro, A., \& Pascoal, A. G. (2013). Resting scapular posture in healthy

940 overhead throwing athletes. Manual Therapy, 18, 547-550. 
941 Roddey, T. S., Olson, S. L., \& Grant, S. E. (2002). The Effect of Pectoralis Muscle Stretching on the Resting Position of the Scapula in Persons with Varying Degrees of Forward Head/Rounded Shoulder Posture. Journal of Manual \& Manipulative Therapy, 10, 124-128.

945 Sahrmann, S. A. (2002). Diagnosis and Treatment of Movement Impairment $946 \quad$ Syndromes. St Louis, MO: Mosby.

947 Shahidi, B., Johnson, C., Curran-Everett, D., \& Maluf, K. (2012). Reliability 948 and group differences in quantitative cervicothoracic measures among 949 individuals with and without chronic neck pain. BMC Musculoskeletal $950 \quad$ Disorders, 13, 215.

951 Sobush, D. C., Simoneau, G. G., Dietz, K. E., Levene, J. A., Grossman, R. 952 E., \& Smith, W. B. (1996). The lennie test for measuring scapular position in healthy young adult females: a reliability and validity study. Journal of Orthopaedic and Sports Physical Therapy, 23, 39-50.

955 Struyf, F., Meeus, M., Fransen, E., Roussel, N., Jansen, N., Truijen, S., \& $956 \quad$ Nijs, J. (2014). Interrater and intrarater reliability of the pectoralis 957 minor muscle length measurement in subjects with and without 958 shoulder impingement symptoms. Manual Therapy, 19, 294-298.

959 Struyf, F., Nijs, J., Horsten, S., Mottram, S., Truijen, S., \& Meeusen, R. 960 (2011). Scapular positioning and motor control in children and adults: 961 A laboratory study using clinical measures. Manual Therapy, 16, 155962160.

963 Struyf, F., Nijs, J., Meeus, M., Roussel, N. A., Mottram, S., Truijen, S., \& 964 Meeusen, R. (2014). Does Scapular Positioning Predict Shoulder Pain 
in Recreational Overhead Athletes? International Journal of Sports Medicine, 35, 75-82.

967 Tate, A., Turner, G. N., Knab, S. E., Jorgensen, C., Strittmatter, A., \& Michener, L. A. (2012). Risk Factors Associated With Shoulder Pain and Disability Across the Lifespan of Competitive Swimmers. Journal of Athletic Training, 47, 149-158.

971 Thigpen, C. A., Padua, D. A., Michener, L. A., Guskiewicz, K., Giuliani, C., Keener, J. D., \& Stergiou, N. (2010). Head and shoulder posture affect scapular mechanics and muscle activity in overhead tasks. Journal of electromyography and kinesiology : official journal of the International

976 Tsai, N. T., McClure, P. W., \& Karduna, A. R. (2003). Effects of muscle fatigue on 3-dimensional scapular kinematics. Archives of Physical Medicine and Rehabilitation, 84, 1000-1005.

979 Uhl, T. L., Kibler, W. B., Gecewich, B., \& Tripp, B. L. (2009). Evaluation of 980 Clinical Assessment Methods for Scapular Dyskinesis. Arthroscopy : 981 the journal of arthroscopic \& related surgery : official publication of the 982 Arthroscopy Association of North America and the International Arthroscopy Association, 25, 1240-1248.

984 Wang, C. H., McClure, P., Pratt, N. E., \& Nobilini, R. (1999). Stretching and 985 strengthening exercises: their effect on three-dimensional scapular $986 \quad$ kinematics. Archives of Physical Medicine and Rehabilitation, 80, 923987 929.

988 Weon, J.-H., Kwon, O.-Y., Cynn, H.-S., Lee, W.-H., Kim, T.-H., \& Yi, C.-H. 989 (2011). Real-time visual feedback can be used to activate scapular 
upward rotators in people with scapular winging: an experimental study. Journal of Physiotherapy, 57, 101-107.

992 Weon, J.-H., Oh, J.-S., Cynn, H.-S., Kim, Y.-W., Kwon, O.-Y., \& Yi, C.-H.

993 (2010). Influence of forward head posture on scapular upward rotators 994 during isometric shoulder flexion. Journal of Bodywork and Movement $995 \quad$ Therapies, 14, 367-374.

996 Weppler, C. H., \& Magnusson, S. P. (2010). Increasing Muscle Extensibility: 997 A Matter of Increasing Length or Modifying Sensation? Physical $998 \quad$ Therapy, 90, 438-449.

999 Williams, J. G., Laudner, K. G., \& McLoda, T. (2013). The acute effects of 1000 two passive stretch maneuvers on pectoralis minor length and scapula 1001 kinematics among collegiate swimmers. The International Journal of 1002 Sports Physical Therapy, 8, 25-33.

1003 Wong, C. K., Coleman, D., diPersia, V., Song, J., \& Wright, D. (2010). The 1004 effects of manual treatment on rounded-shoulder posture, and 1005 associated muscle strength. Journal of Bodywork and Movement $1006 \quad$ Therapies, 14, 326-333.

\section{Captions to figures}

1010

1011 Figure 1. Proposed associations between pectoralis minor muscle (PMm)

1012 tightness, altered scapular position and motion and shoulder/neck pain 1013 syndromes. Pectoralis minor muscle tightness can be a primary or secondary 
1014 mechanism of shoulder movement impairments and pain (two-way arrow).

$1015 \mathrm{GH}$, Glenohumeral

1016

1017 Figure 2. Direct measurement of the pectoralis minor muscle length in the

1018 standing upright position. The therapist palpates and measures the length

1019 between the medial-inferior angle of the coracoid process and the inferior

1020 aspect of the $4^{\text {th }}$ rib near its junction with the sternum.

1021

1022 Figure 3. Scapular and upper quadrant mobility assessment. The

1023 extensibility of the pectoralis minor muscle is estimated by moving the

1024 scapula from rest to full retraction and posterior tilting (first two frames).

1025 Postural mobility of the head, cervical and thoracic spines (green arrows)

1026 and compensatory movements (red arrows) are shown in the last two

1027 frames. Blue arrow represents the schematic line of action of the pectoralis

1028 minor muscle and the direction of tension.

1029

1030 Figure 4. Complementary assessment of the relationships between

1031 pectoralis minor length and the axial skeleton. Retraction and posterior

1032 tilting of the scapulae leads to an elevation of the upper thorax, which limits

1033 the pectoralis minor muscle full lengthening capacity (first two frames). Deep

1034 progressive expirations are encouraged to descend the upper thorax while

1035 keeping the scapulae close to the treatment table (last two frames). Green

1036 arrows indicate the actions of the patient, therapist or both. Red arrows

1037 represent the compensatory movements of the upper thorax or scapulae to

1038 the actions of the patient, therapist or both. Blue arrow represents the 
1039 schematic line of action of the pectoralis minor muscle and the direction of

1040 tension.

1041

1042 Figure 5. Technique to stretch the pectoralis minor muscle throughout

1043 shoulder abduction. The therapist presses the coracoid process superiorly

1044 and posteriorly to stretch the muscle, stabilizes the thorax preventing

1045 misalignments and assists in the depression of the $3^{\text {rd }}, 4^{\text {th }}$ and $5^{\text {th }}$ ribs. The

1046 patient performs deep progressive expirations to descend the upper thorax

1047 while keeping the scapulae close to the treatment table. A contract-relax

1048 technique (forward movement of the scapula) can be performed whenever

1049 points of tightness are felt (last frame). Green arrows indicate actions of the

1050 patient, therapist or both. Blue arrow represents the schematic line of action

1051 of the pectoralis minor muscle and the direction of tension.

1052

1053 Figure 6. Maneuvers of the therapist to improve the alignment and mobility

1054 of the thoracic spine. Green arrows represent the direction of the maneuvers

1055 directed to improve the alignment and the mobility (rotations and

1056 translations) of the thoracic spine. These maneuvers can be applied at

1057 different ranges of motion of shoulder abduction, whenever maintenance of

1058 the alignment and mobility of the spine and thorax throughout the stretching

1059 is difficult (see text for details).

1060 
${ }^{*}$ Acknowledgements

Acknowledgments
None

Acknowledgments
None

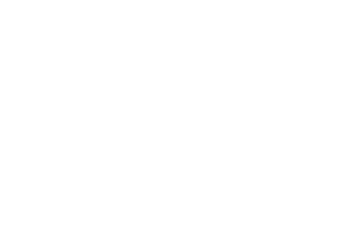

thos

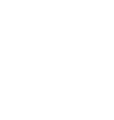

Ack

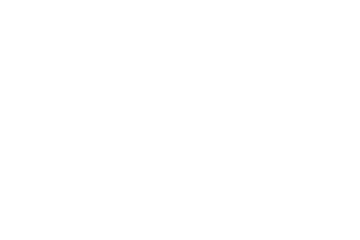

Ack
Nor

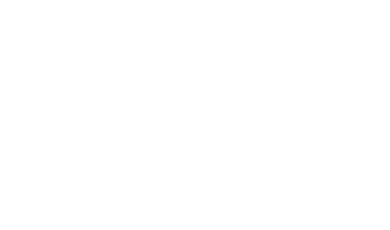

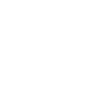

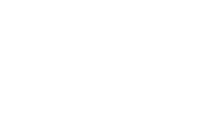

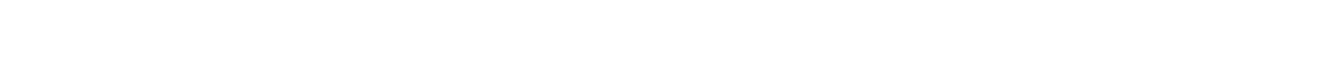


TABLE 1. Measurement properties of the clinical methods used to assess the pectoralis minor muscle length

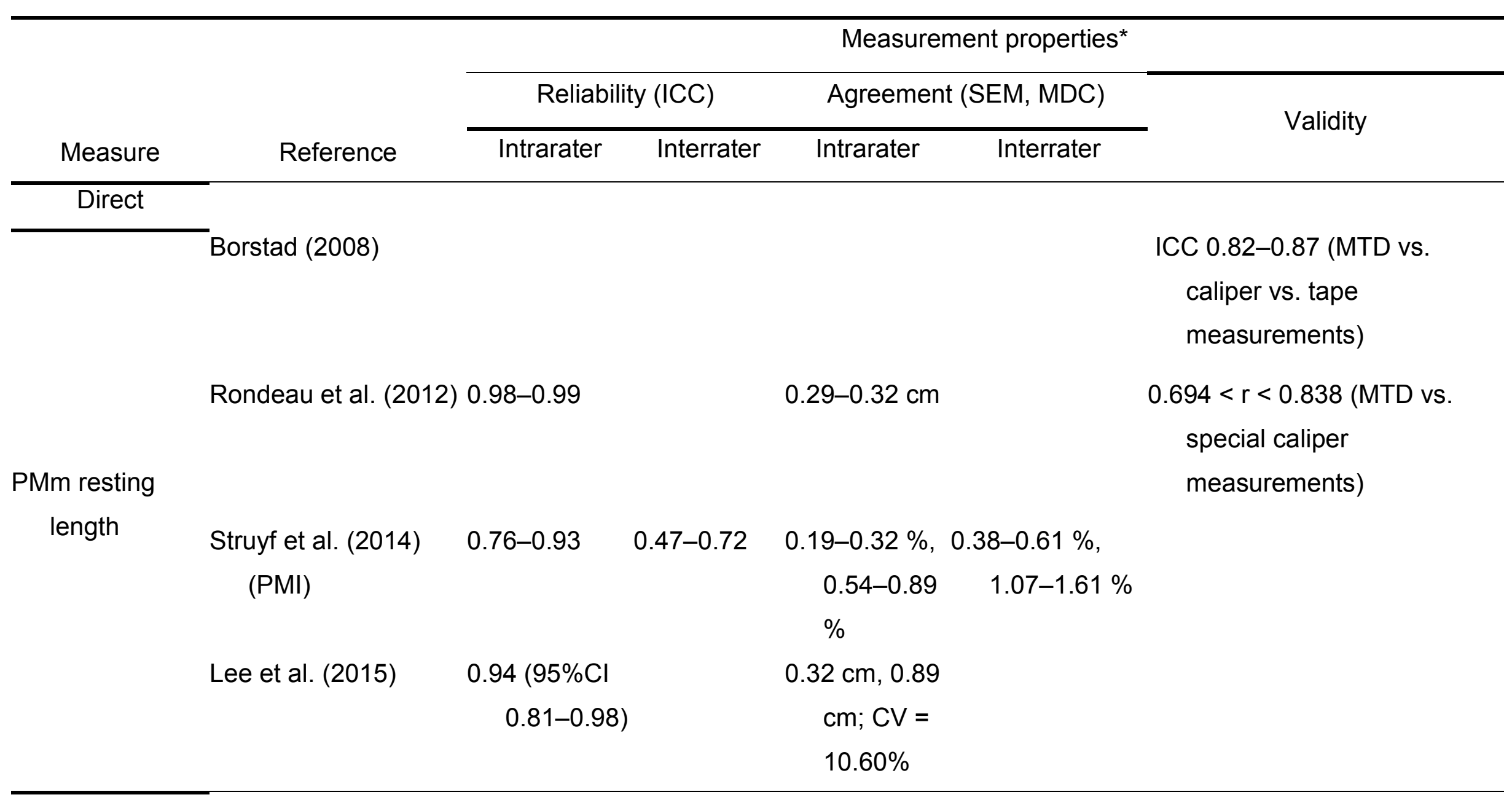




\begin{tabular}{|c|c|c|c|c|c|}
\hline Indirect & & & & & \multirow{6}{*}{$0.10<r<0.16$ with PMI } \\
\hline \multirow{5}{*}{ PMm length test } & \multicolumn{2}{|l|}{ Nijs et al. (2005) } & $0.88-0.94$ & $0.23-0.46 \mathrm{~cm}$ & \\
\hline & \multicolumn{2}{|l|}{ Borstad (2006) } & & & \\
\hline & $\begin{array}{l}\text { Lewis \& Valentine } \\
\qquad(2007)\end{array}$ & $0.90-0.97$ & & $0.34-0.45 \mathrm{~cm}$ & \\
\hline & Wong et al.(2010) & $0.80(0.68-$ & & \multirow[t]{2}{*}{$0.12 \mathrm{~cm}$} & \\
\hline & \multicolumn{3}{|c|}{$0.88)$} & & \\
\hline \multirow{8}{*}{$\begin{array}{l}\text { Forward } \\
\text { shoulder } \\
\text { posture }\end{array}$} & \multicolumn{3}{|l|}{ Linear measurement } & & \\
\hline & \multicolumn{2}{|c|}{ Peterson et al. (1997) 0.89-0.99 } & & SEE $\sim 1.1 \mathrm{~cm}$ & $\begin{array}{l}r^{2} 0.30-0.59 \text { with radiographic } \\
\text { measurements }\end{array}$ \\
\hline & \multicolumn{2}{|l|}{ Struyf et al.(2009) } & 0.72 & $1.7 \mathrm{~cm}, 4.71 \mathrm{~cm}$ & \\
\hline & \multicolumn{2}{|l|}{ Laudner et al.(2010) } & & & $\begin{array}{c}r^{2}=0.50 \text { with posterior } \\
\text { shoulder tightness }\end{array}$ \\
\hline & \multirow[t]{4}{*}{ Lee et al. (2015) } & & & & $r=0.89$ and $r_{a d j}^{2}=0.78$ with \\
\hline & & & & & PMI \\
\hline & & & & & $\begin{aligned} r= & 0.72 \text { with posterior shoulder } \\
& \text { tightness }\end{aligned}$ \\
\hline & & & & & $r=0.72$ with thoracic kyphosis \\
\hline
\end{tabular}




\begin{tabular}{|c|c|c|c|c|c|c|}
\hline & Angular measuremen & & & & & \\
\hline & Lewis et al. (2005) & $\begin{array}{c}0.99(0.99- \\
1.0)\end{array}$ & $\begin{array}{c}0.93(0.78- \\
0.99)\end{array}$ & $0.5^{\circ}$ & $1.4^{\circ}$ & \\
\hline & Gibson et al. (1995) & $0.88-0.95$ & $0.18-0.92$ & $0.44-0.79 \mathrm{~cm}$ & $0.65-1.65 \mathrm{~cm}$ & \\
\hline & Sobush et al. (1996) & $0.84-0.96$ & $0.76-0.92$ & & & $\begin{array}{l}0.76<r<0.82 \text { with } \\
\text { radiographic measurements } \\
\text { Scoliometer vs. radiographic } \\
\quad \text { measurements mean } \\
\text { differences } 0.03-0.56 \mathrm{~cm}\end{array}$ \\
\hline $\begin{array}{l}\text { Scapular } \\
\text { protraction }\end{array}$ & Kibler (1998) & $0.84-0.88$ & $0.77-0.85$ & & & $\begin{aligned} r= & 0.91 \text { with radiographic } \\
& \text { measurements }\end{aligned}$ \\
\hline measuremen & tMcKenna et al. (2004 & ) $0.85-0.94$ & $0.20-0.87$ & & $\begin{array}{l}0.53-1.19 \mathrm{~cm}, \\
1.46-3.32 \mathrm{~cm}\end{array}$ & \\
\hline & Morais (2009) & & & & & $\begin{aligned} r> & 0.75 \text { with anthropometrics } \\
& \text { of the upper quadrant } \\
& \text { (Morais, 2009) } \\
r< & 0.50 \text { with 3D scapular } \\
& \text { position (MTD) }\end{aligned}$ \\
\hline
\end{tabular}


Borstad (2006)

Scapula index

(SI)

Morais (2009)
SI

$r=0.30$ with scapular internal rotation (MTD)

$\mathrm{SN}$ to $\mathrm{CP}$

$r=0.48$ with PMI (J. D.

Borstad, 2006)

SI

$0.60<r<0.65$ with scapular internal rotation (MTD)

ThS to PLA

$0.6 \mathrm{~cm}, 1.8$

$\mathrm{cm}$

Linear measurement

Weon et al. (2011) $0.97(0.87-\quad 0.1 \mathrm{~cm}$

Scapular winging

or tilting

$0.99)$

Angular measurement

Plafcan et al. (1997)

$0.97-0.99 \quad 0.92-0.97 \quad 0.6-1.1^{\circ} \quad 1.1^{\circ}-1.7^{\circ}$ 
Abbreviations: 3D, three-dimensional; 95\% Cl, 95\% confidence intervals; $\mathrm{CP}$, coracoid process; CV, coefficient of variation; MTD, motion tracking device; ICC, intraclass correlation coefficient; MDC, minimal detectable change; PLA, posterolateral angle of the acromion; PMI, pectoralis minor index; PMm, pectoralis minor muscle; $r$, correlation coefficient; $r^{2}$, coefficient of determination; SEE, standard estimate of error; SEM, standard error of the measurement; SN, sternal notch; ThS, thoracic spine.

* Reliability has been assessed with the Intraclass Correlation Coefficient (ICC) and agreement with the standard error of measurement (SEM) and minimal detectable change (MDC), in centimeters, unless otherwise stated. 


\section{Stretching techniques used to increase the pectoralis minor muscle length}

\begin{tabular}{|c|c|c|}
\hline Reference & Position & Technique \\
\hline \multicolumn{3}{|c|}{ Self-stretching } \\
\hline $\begin{array}{l}\text { Bang \& Deyle } \\
\qquad(2000)\end{array}$ & $\begin{array}{l}\text { Standing, with shoulders abducted at } 90^{\circ} \text {, } \\
\text { elbows flexed at } 90^{\circ} \text { and the palm of the } \\
\text { hands and forearms placed on a flat } \\
\text { surface (adjacent walls or a doorframe); } \\
\text { known as the bilateral corner stretch. }\end{array}$ & $\begin{array}{l}\text { The patient leans the body forward into adjacent walls } \\
\text { of a corner or a doorframe. }\end{array}$ \\
\hline $\begin{array}{l}\text { Lawson et al. } \\
\qquad(2011)\end{array}$ & $\begin{array}{l}\text { Sitting on a chair, with the hands resting on } \\
\text { the armrests. }\end{array}$ & $\begin{array}{l}\text { The patient lifts his/her upper body with the full } \\
\text { extension of the elbows to detach the upper body } \\
\text { from the seat. The lengthening of the PMm is } \\
\text { obtained by dropping the body weight until maximum } \\
\text { shrug of the shoulders is reached. }\end{array}$ \\
\hline $\begin{array}{l}\text { Lee et al. } \\
\qquad(2007)\end{array}$ & Supine & $\begin{array}{l}\text { The arm is positioned at } 135^{\circ} \text { of shoulder abduction and } \\
\text { held externally rotated with a } 2 \mathrm{~kg} \text { weight. }\end{array}$ \\
\hline Lynch et al. & Supine, with a towel or foam roll along the & The patient starts with both shoulders and elbows flexed \\
\hline
\end{tabular}


(2010) spine.

at $90^{\circ}$, so that the forearms and palms are touching.

Patient then horizontally abducts the shoulders and

retracts the scapulas whilst flattening the spine

against the roll.

Wang et al. Standing, with shoulder abducted at $90^{\circ}$, The patient rotates the trunk away from the elevated

(1999) elbow flexed at $90^{\circ}$ and the palm of the arm without moving the feet, thus increasing the hand and forearm placed on a flat surface horizontal abduction of the shoulder.

(wall or doorframe); known as the unilateral corner stretch.

Wong et al. Supine, with knees bent and legs rotated to (2010) the floor, in the opposite direction of the arm to be stretched.

The patient slowly brings the arm in a circular motion overhead pausing at points of tightness, maintaining close contact to the mat.

\section{Manual stretching}

\begin{tabular}{|c|c|c|}
\hline $\begin{array}{l}\text { Borstad \& } \\
\qquad \text { Ludewig } \\
\text { (2006) }\end{array}$ & $\begin{array}{l}\text { Supine, with a towel or foam roll along the } \\
\text { spine. }\end{array}$ & $\begin{array}{l}\text { The therapist positions patient's shoulder at } 90^{\circ} \text { of } \\
\text { abduction and external rotation and the elbow at } 90^{\circ} \\
\text { flexion while applying a posterior force to CP. }\end{array}$ \\
\hline
\end{tabular}

Kendall et al. Supine, with the knees bent and arms at side. The therapist applies a diagonal force to CP in the 

(2005) A towel or foam roll can be placed along the spine.

Kisner \& $\quad$ Upright sitting position without back support The patient inhales deeply and holds the breath while

Colby and arms at side.

(2007) opposite direction of the PMm fibers (posterior, lateral and superior direction). To avoid any rotation of patient's trunk, the force is applied on both shoulders. posterior force to $\mathrm{CP}$ and stabilizing the inferior

angle of the scapula. The patient then exhales while the therapist holds the position.

Abbreviations: $\mathrm{CP}$, coracoid process; $\mathrm{PMm}$, pectoralis minor muscle

\section{References}

Bang, M. D., \& Deyle, G. D. (2000). Comparison of supervised exercise with and without manual physical therapy for patients with shoulder impingement syndrome. Journal of Orthopaedic and Sports Physical Therapy, 30, 126-137.

Borstad, J. D., \& Ludewig, P. M. (2006). Comparison of three stretches for the pectoralis minor muscle. Journal of Shoulder and Elbow Surgery, 15, 324-330. 
Kendall, F. P., McCreary, E. K., Provance, P. G., Rodgers, M. M., \& Romani, W. A. (2005). Muscles: Testing and Function with Posture and Pain (5th ed ed.). Baltimore, MD: Lippincott, Williams, \& Wilkins.

Kisner, C., \& Colby, L. A. (2007). Therapeutic Exercise: Foundations and Techniques (5th ed ed.). Philadelphia, PA: F.A. Davis.

Lawson, G. E., Hung, L. Y., Ko, G. D., \& Laframboise, M. A. (2011). A case of pseudo-angina pectoris from a pectoralis minor trigger point caused by cross-country skiing. Journal of Chiropractic Medicine, 10, 173-178.

Lee, T. S., Kilbreath, S. L., Refshauge, K. M., Pendlebury, S. C., Beith, J. M., \& Lee, M. J. (2007). Pectoral stretching program for women undergoing radiotherapy for breast cancer. Breast Cancer Research and Treatment, 102, 313-321.

Lynch, S. S., Thigpen, C. A., Mihalik, J. P., Prentice, W. E., \& Padua, D. (2010). The effects of an exercise intervention on forward head and rounded shoulder postures in elite swimmers. British Journal of Sports Medicine, 44, 376-381.

Wang, C. H., McClure, P., Pratt, N. E., \& Nobilini, R. (1999). Stretching and strengthening exercises: their effect on threedimensional scapular kinematics. Archives of Physical Medicine and Rehabilitation, 80, 923-929.

Wong, C. K., Coleman, D., diPersia, V., Song, J., \& Wright, D. (2010). The effects of manual treatment on rounded-shoulder posture, and associated muscle strength. Journal of Bodywork and Movement Therapies, 14, 326-333. 


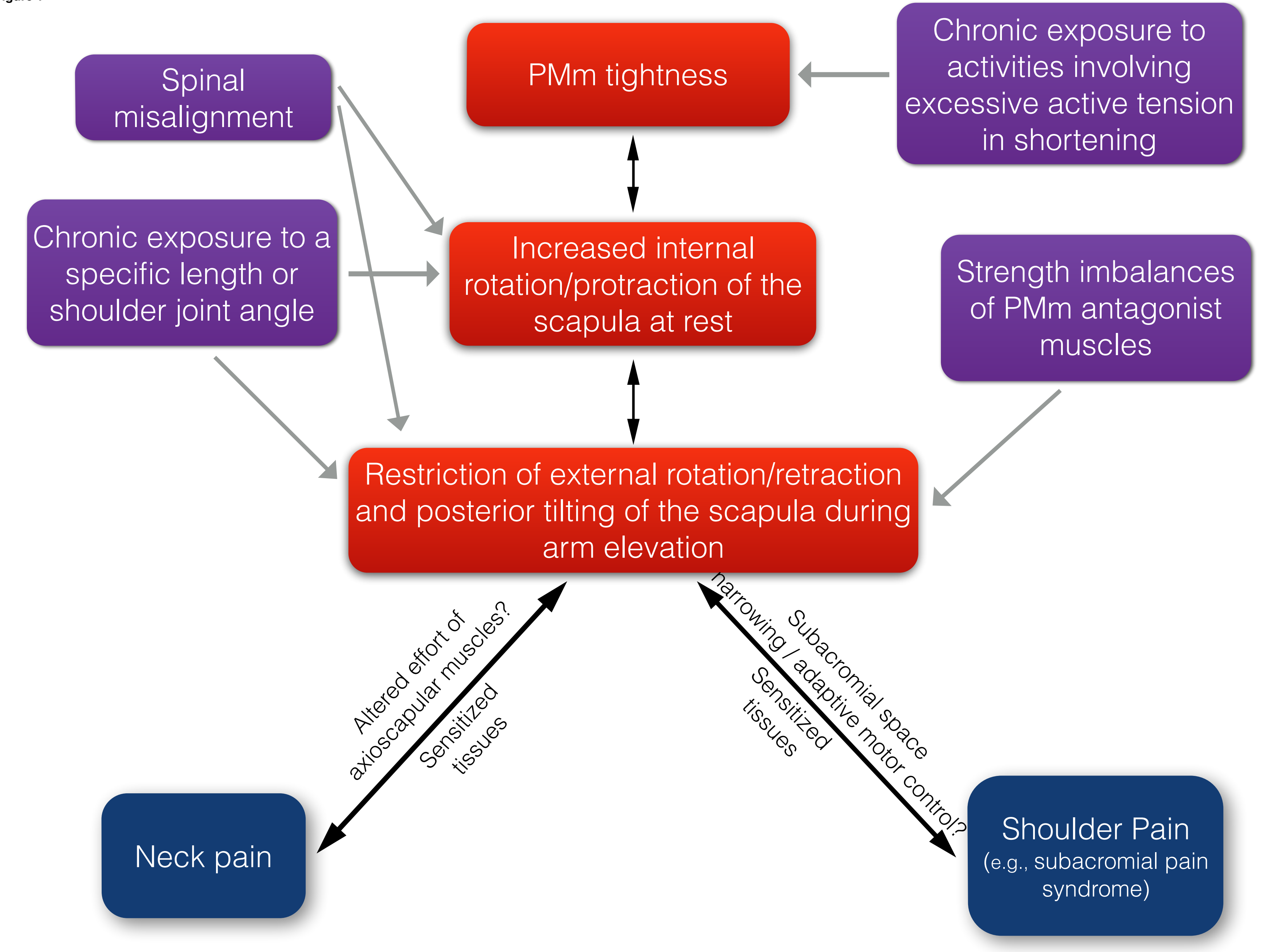
specific length or shoulder joint angle
Shoulder Pain syndrome) 


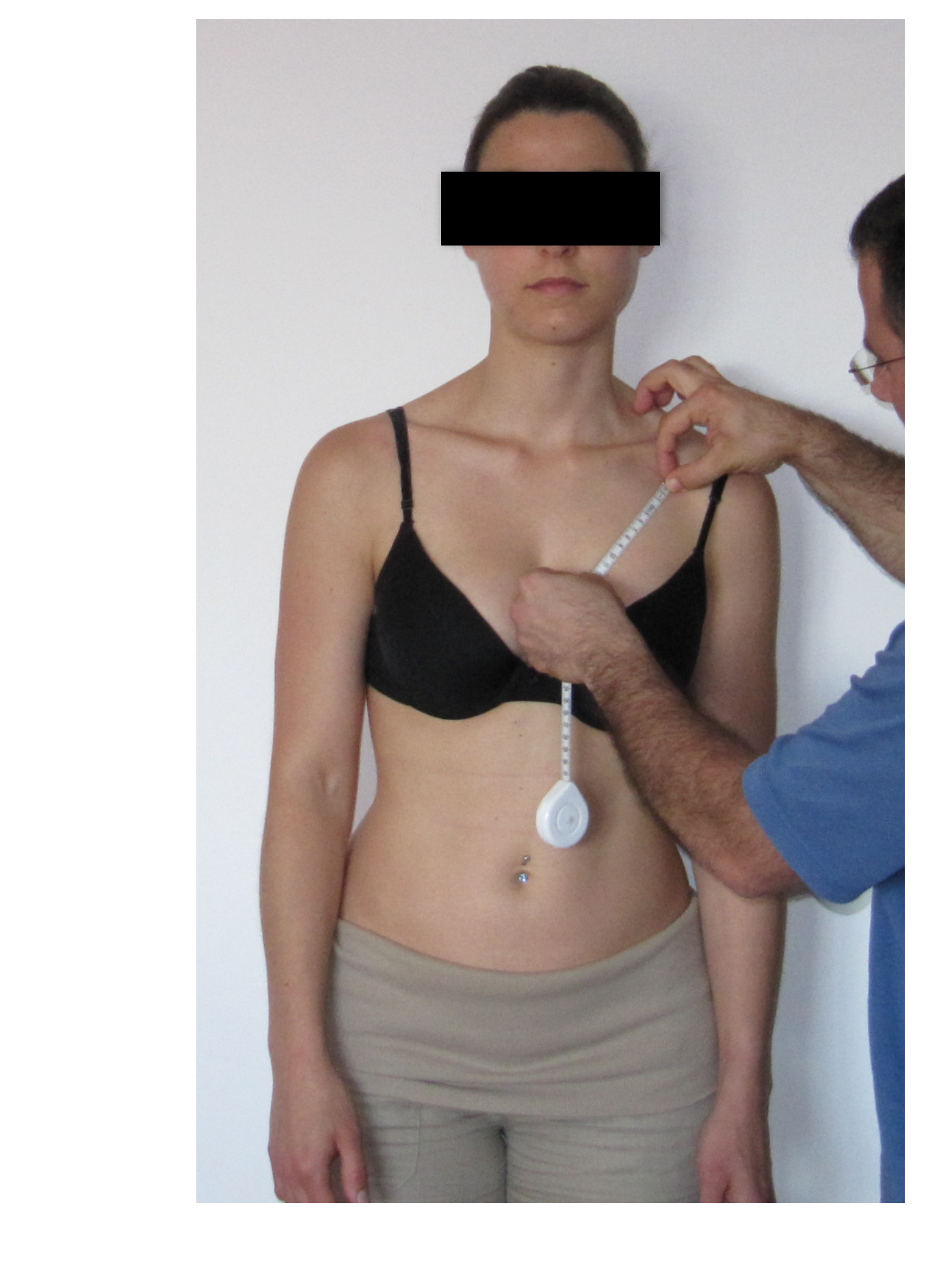

(⿸丆口
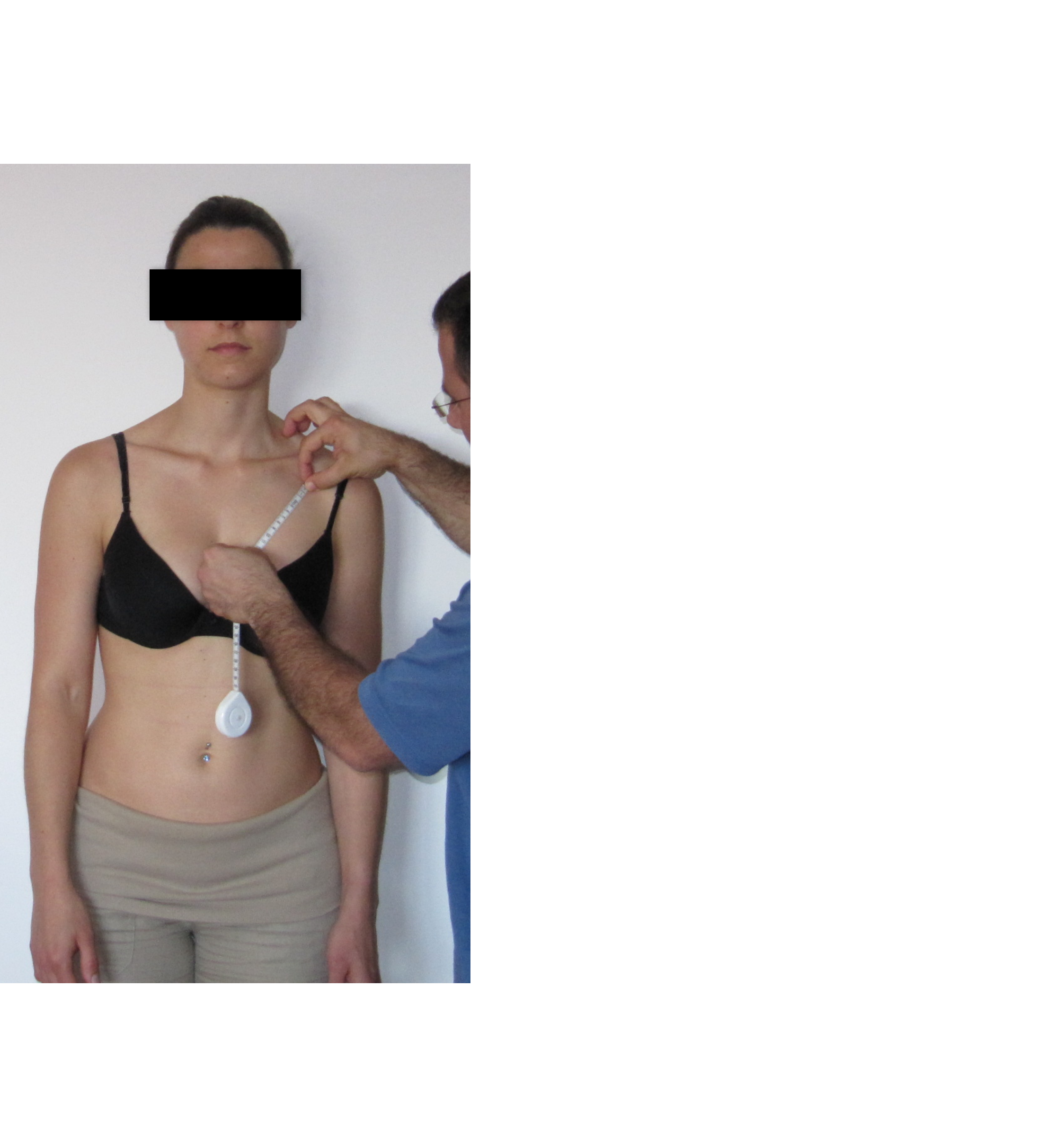


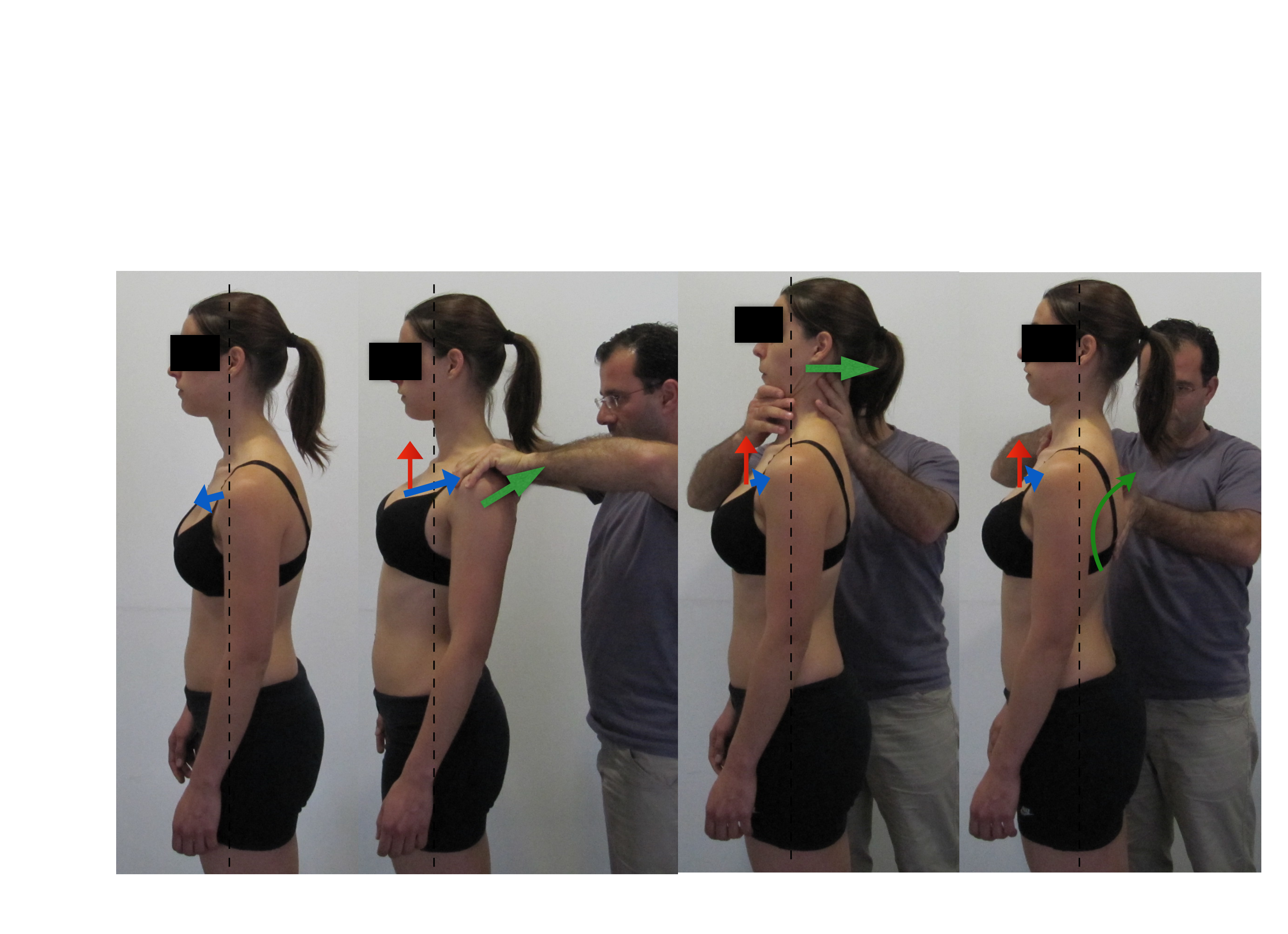

Figure

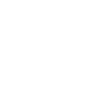
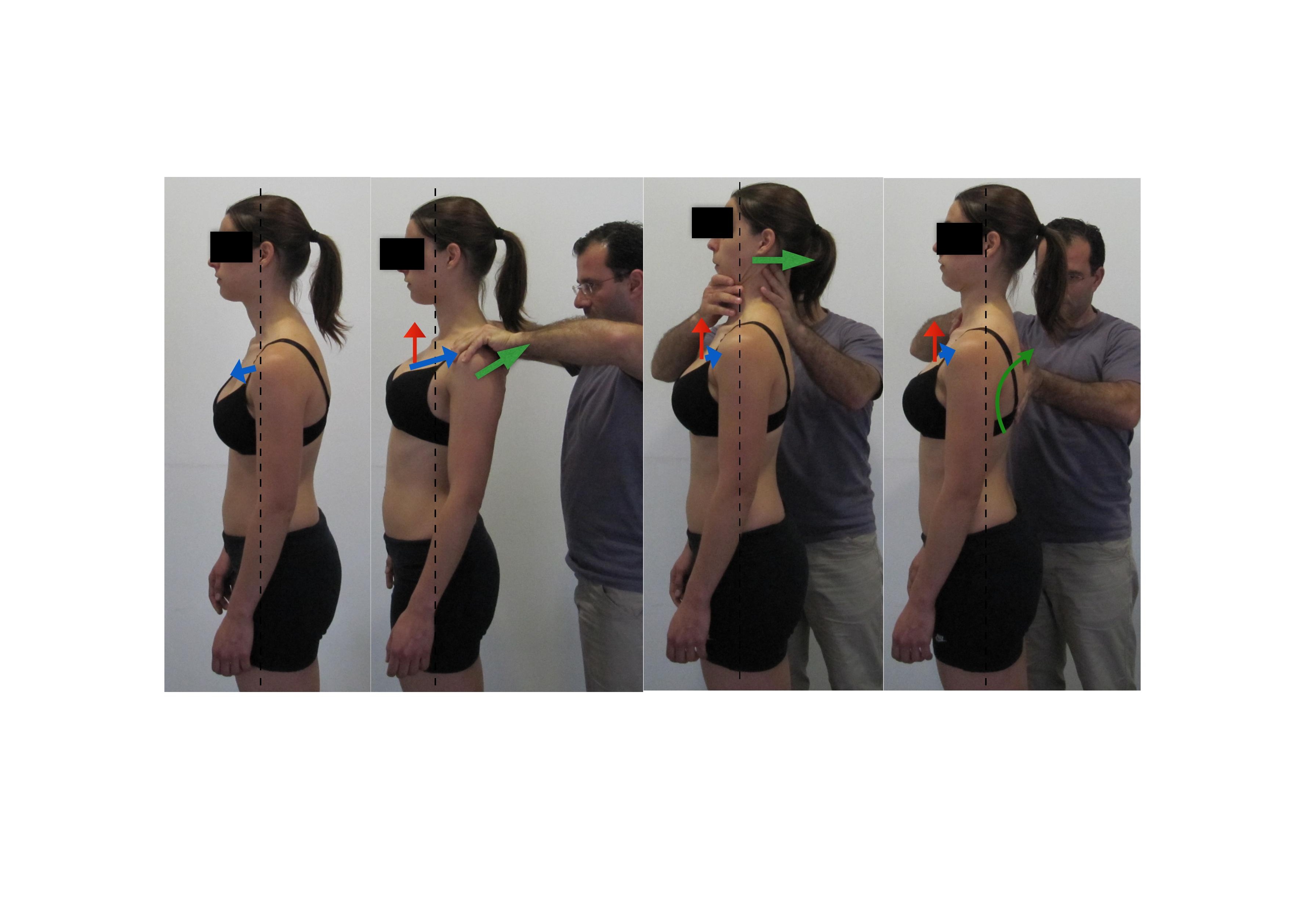

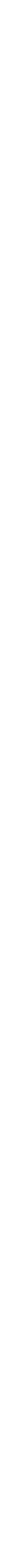